\title{
VARIABLE CANT ANGLE WINGLETS FOR IMPROVEMENT OF AIRCRAFT FLIGHT PERFORMANCE
}

$\begin{array}{ccc} & \text { A PREPRINT } & \\ \text { Joel E. Guerrero } & & \\ \text { DICCA } & \text { Marco Sanguineti } & \text { Kevin Wittkowski } \\ \text { DICCA } \\ \text { Università degli Studi di Genova } \\ \text { Genova, Italy } & \text { Università degli Studi di Genova } & \text { Università degli Studi di Genova } \\ \text { joel.guerrero@unige.it } & \text { Genova, Italy } & \text { Genova, Italy }\end{array}$

June 28, 2019

\begin{abstract}
Traditional winglets are designed as fixed devices attached at the tips of the wings. The primary purpose of the winglets is to reduce the lift-induced drag, therefore improving aircraft performance and fuel efficiency. However, because winglets are fixed surfaces, they cannot be used to control lift-induced drag reductions or to obtain the largest lift-induced drag reductions at different flight conditions (take-off, climb, cruise, loitering, descent, approach, landing, and so on). In this work, we propose the use of variable cant angle winglets which could potentially allow aircraft to get the best all-around performance (in terms of lift-induced drag reduction), at different flight phases. By using computational fluid dynamics, we study the influence of the winglet cant angle and sweep angle on the performance of a benchmark wing at Mach numbers of 0.3 and 0.8395 . The results obtained demonstrate that by adjusting the cant angle, the aerodynamic performance can be improved at different flight conditions.
\end{abstract}

Keywords Variable cant angle $\cdot$ Winglets $\cdot$ Drag reduction $\cdot$ Lift-induced drag $\cdot$ CFD

\section{Nomenclature}

$a$

$A O A$

$A O A_{\text {eff }}$

$A O A_{\text {ind }}$

$C_{D}$

$C_{D_{\min }}$

$C_{L}$

$C_{L_{0}}$

$C_{L_{\max }}$

$C_{L} / C_{D}$

$C_{P}$

$M a$

$C_{1}$

$C_{2}$

D

speed of sound, measured in $\mathrm{m} / \mathrm{s}$.

angle-of-attack, measured in degrees $\left(^{\circ}\right)$.

effective angle-of-attack, measured in degrees $\left({ }^{\circ}\right)$.

induced angle-of-attack, measured in degrees $\left(^{\circ}\right)$.

drag coefficient, nondimensional.

minimum drag coefficient, nondimensional.

lift coefficient, nondimensional.

lift coefficient at zero angle-of-attack, nondimensional.

maximum lift coefficient, nondimensional.

lift-to-drag ratio, nondimensional.

pressure coefficient, nondimensional.

Mach number, nondimensional.

Sutherland model coefficient, $1.458 \times 10^{-6} \mathrm{~kg} /\left(\mathrm{m}-s-K^{0.5}\right)$.

Sutherland model coefficient, $110.4 \mathrm{~K}$.

drag force, measured in $N$. 


$\begin{array}{ll}L & \text { lift force, measured in } N . \\ P & \text { local pressure, measured in } \mathrm{Pa} . \\ P_{\infty} & \text { freestream pressure, measured in } \mathrm{Pa} . \\ R e & \text { Reynolds number, nondimensional. } \\ S_{r e f} & \text { reference surface area, measured in } \mathrm{m}^{2} . \\ T & \text { local temperature, measured in } \mathrm{K} . \\ T_{\infty} & \text { freestream temperature, measured in } \mathrm{K} . \\ R & \text { air specific gas constant, } 287.058 \mathrm{~J} /(\mathrm{kg}-\mathrm{K}) . \\ V & \text { local velocity, measured in } \mathrm{m} / \mathrm{s} . \\ V_{\infty} & \text { freestream velocity, measured in } \mathrm{m} / \mathrm{s} . \\ w & \text { downwash, measured in } \mathrm{m} / \mathrm{s} . \\ y^{+} & \text {viscous wall units, nondimensional. }\end{array}$

\section{Greek Symbols}

$\begin{array}{ll}\alpha_{z l} & \text { angle-of-attack at zero lift, measured in degrees }\left(^{\circ}\right) . \\ \Delta C_{D} & \text { drag count, } 1 \Delta C_{D}=10000 \times C_{D} \text {, nondimensional. } \\ \partial C_{L} / \partial A O A & \text { slope of the lift curve, measured in } 1 /{ }^{\circ} . \\ \rho & \text { density, measured in } \mathrm{kg} / \mathrm{m}^{3} . \\ \gamma & \text { air ratio of specific heat, } 1.4, \text { nondimensional. } \\ \mu & \text { dynamic viscosity, measured in } \mathrm{kg} /(\mathrm{m}-\mathrm{s}) . \\ \kappa & \text { turbulent kinetic energy, measured in } \mathrm{m}^{2} / \mathrm{s}^{2} . \\ \omega & \text { specific dissipation rate, measured in } 1 / \mathrm{s} .\end{array}$

\section{Acronyms}

$\begin{array}{ll}\text { ACARE } & \text { Advisory Council for Aviation Research in Europe. } \\ \text { CFD } & \text { Computational Fluid Dynamics. } \\ \text { RANS } & \text { Reynolds-Averaged Navier-Stokes. } \\ \text { SIMPLE } & \text { Semi-Implicit Method for Pressure Linked Equations. } \\ \kappa-\omega \text { SST } & \text { Menter's Shear Stress Transport turbulence model. } \\ \mathrm{CO}_{2} & \text { Carbon Dioxide. } \\ \mathrm{NOx} & \text { Nitrogen Oxide. } \\ \text { WWSWI } & \text { Wing-Winglet Shock Wave Interaction. }\end{array}$

\section{Introduction}

Regulatory civil aviation agencies are pushing aircraft manufacturers and operators to improve aircraft efficiency by reducing fuel consumption, cutting carbon dioxide $\mathrm{CO}_{2}$ and nitrogen oxide $\mathrm{NOx}$ emissions, and lowering the perceived external noise. One way to help achieve this goal is by using improved and innovative technologies targeting drag reduction, specifically, lift-induced drag reduction. The drag breakdown of a typical transport aircraft shows that the lift-induced drag can amount to as much as $40 \%$ of the total drag at cruise conditions and $80-90 \%$ of the total drag

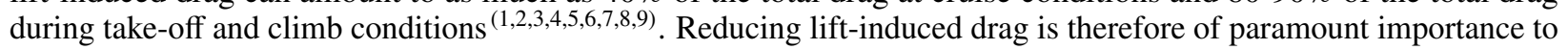
improve aircraft efficiency.

One way to reduce the lift-induced drag is by increasing the wingspan. However, increased wingspan requires strengthening the wing structure so that it can withstand the increased bending moments. Increasing the wingspan can also pose limitations in airport ground operations and gate clearance requirements. Another way of reducing lift-induced drag is by using wingtip devices, such as winglets (as illustrated in figure 1 . Winglets do not all look the same; nevertheless, their ultimate goal is always lift-induced drag reduction by artificially increasing the span of the 

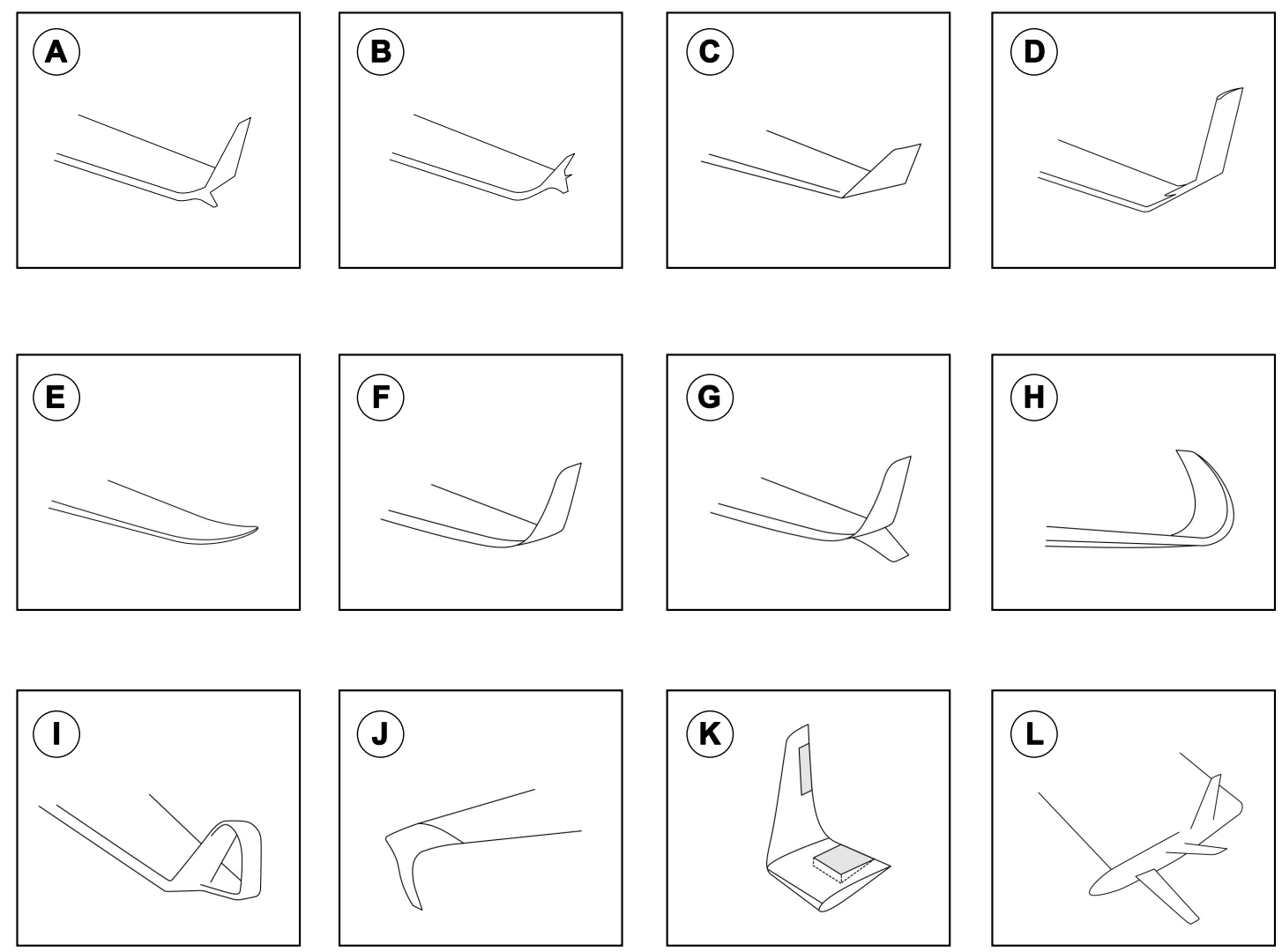

Figure 1: Different types of winglets and wingtip devices. A) Whitcomb winglet. B) Tip fence. C) Canted winglet. D) Vortex diffuser. E) Raked winglet. F) Blended winglet. G) Blended split winglet. H) Sharklet. I) Spiroid winglet. J) Downward canted winglet. K) Active winglets. L) Tip sails.

wings. But as for the case of wingspan increment, winglets increase bending moments; therefore, it might be necessary to reinforce the wings. From an aerodynamic point of view winglets are desirable; whereas, from a structural standpoint they are detrimental.

Many studies have found that winglets addition can achieve a fuel burn reduction of about $4 \%$ to $6 \%$, reduce take-off

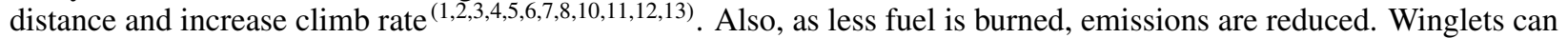
provide up to a $6 \%$ reduction in $\mathrm{CO}_{2}$ emissions and an $8 \%$ reduction in $\mathrm{NOx}$ emissions 14 |15/16. They also increase the aftermarket value of the aircraft and add more aesthetic to the airplane design. Winglets are among the most used fuel saving and performance improvement technologies in today's aviation. The drag reduction gained by adding winglets can be seen as the equivalent decrease in aircraft weight required to carry a payload over a specific distance. A reduction of one drag count in cruise conditions on a subsonic civil transport airplane means about 200 lbs more in payload $^{(17|18| 19)}$ (where one drag count is equal to the drag coefficient $C_{D}$ multiplied by 10000 or $\Delta C_{D}=10000 \times C_{D}$ ). As fuel has a large direct operating cost impact in the air transport industry, fuel consumption reduction is translated in more savings, fewer emissions as less fuel is burn, extended operating range and increased payload.

The increment of wings root bending moment is among the few negative effects of winglets. They also increase parasite drag, which is the contribution of skin friction, interference drag, and pressure drag due to separation. Recall that the total drag of an aircraft or a wing is equal to the sum of parasite drag, lift-induced drag and wave drag. Winglets are aerodynamically viable only when the reduction of lift-induced drag is larger than the increment in parasite drag, and this situation is illustrated in figure 2, where we show the drag polars of two hypothetical wings, one wing with no winglets and one wing with winglets installed.

In figure 2, we can evidence that when operating above the crossover line or the line that passes through the crossover point (which is the point where the two polars intersect), the total drag of the wing with winglets is lower than the total 

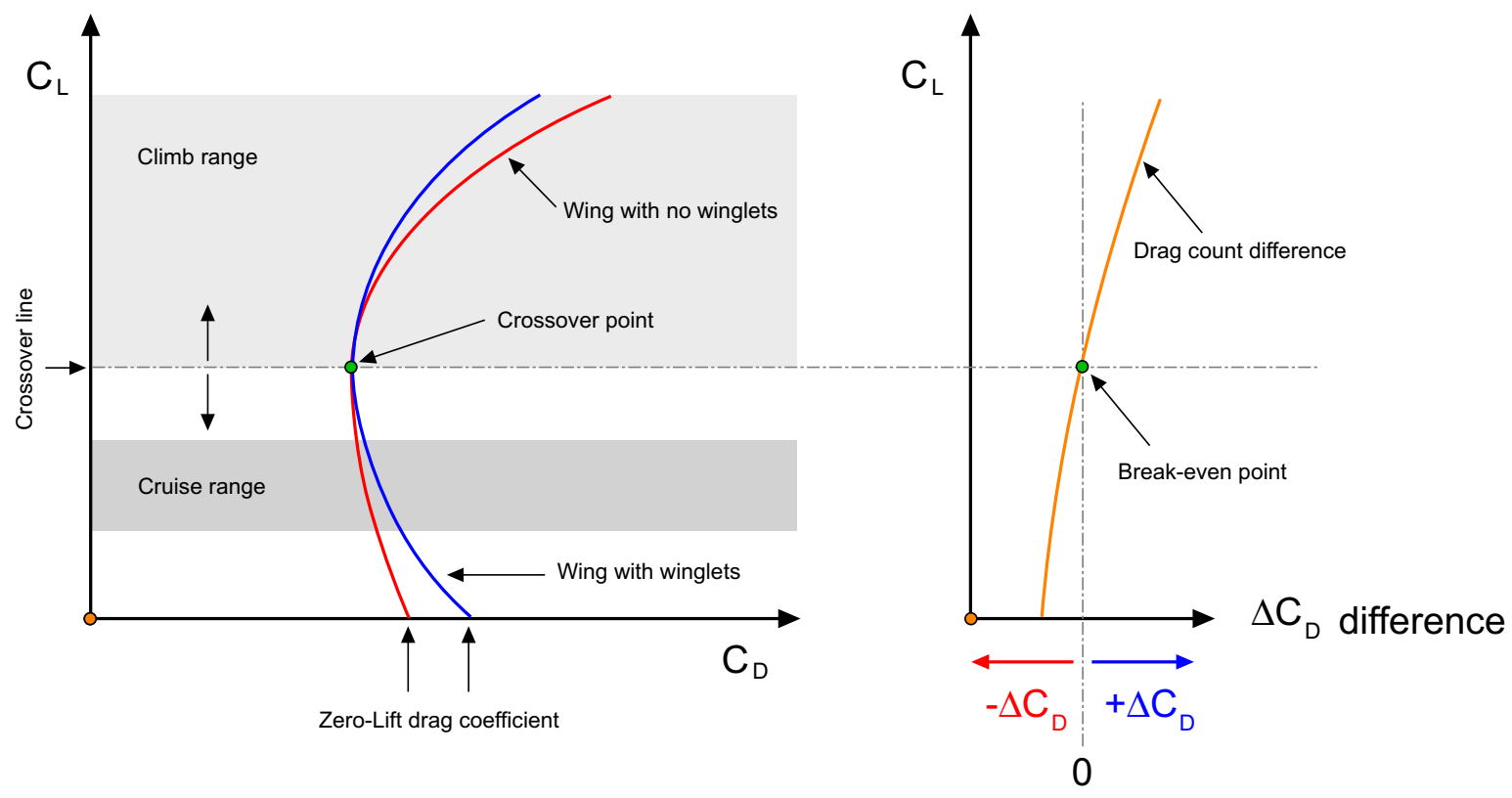

Figure 2: Comparison of drag polars for a wing with no winglets and a wing with winglets installed. In the left image, the light grey area represents the climb range of the wings, and the dark grey area represents the cruise range of the wings. In the right image, we show the drag count difference, where negative $\Delta C_{D}$ means drag increment and positive $\Delta C_{D}$ means drag reduction. The $\Delta C_{D}$ difference is expressed as the drag coefficient $\Delta C_{D}$ subtraction between the wing with winglets and the wing with no winglets.

drag of the wing with no winglets. Conversely, when operating below the crossover line, the total drag of the wing with no winglets is lower than the total drag of the wing with winglets. Therefore, in order to justify the use of winglets in the hypothetical situation illustrated in this figure, we should look at the performance of the wing at a given flight condition. Thus, if the wing were to operate in cruise conditions most of the time (the dark grey region in figure 2), the use of winglets is not justified from a point of view of total drag reduction. On the other hand, if the wing were to operate in climb conditions (the light grey region in figure 22, the use of winglets is justified from an aerodynamic point of view, as the wing generates less drag for a given lift.

As it can be inferred from the previous discussion, the justification of the use of winglets can be based on total drag reduction arguments. So for example and in reference to figure 2 if the crossover point for a given winglet design is located in the cruise region, the use of winglets is justified for that flight condition. The crossover point gives a simple way to measure the total drag reduction trade-off when using winglets. However, winglets use can also be justified in the base of other factors, such as wing (or aircraft) performance at a different altitude. For example, if we climb to a higher altitude where the air is lighter, the wing in discussion would have to flight at a higher angle-of-attack (AOA) that might fall in the light grey region illustrated in figure 2, therefore, the use of winglets is justified based on total drag reduction arguments. As it can be guessed, there might exist different winglet configurations that might shift the crossover point below (or above) what is illustrated in figure 2.

During the 1970s oil crisis, commercial airlines and aircraft manufacturers explored many ways to reduce fuel consumption as a consequence of the high cost of jet fuel. It was not until the late 1970s that R.T. Whitcomb, an engineer at NASA Langley Research Center, pioneered the concept of the modern winglet we see in today's aircraft, as a mean to reduce cruise drag and improve aircraft performance ${ }^{[1112)}$. Whitcomb's work ${ }^{(12)}$, marks the first time a winglet was seriously considered for large and heavy aircraft. Since Whitcomb breakthrough work on winglets, many variations have been designed (as depicted in figure 1], but all of them have been designed as passive or fixed devices attached at the wingtips. That is, the angle between the wing plane and the winglet plane (or cant angle) does not change; therefore, they are designed to deliver lift-induced drag reduction at a single design configuration, which might not be the best winglet configuration to generate the largest lift-induced drag reduction during different flight phases.

Hereafter, we propose the use of variable cant angle winglets that can be actuated by a mechanism (which is not described in this study). In the proposed arrangement, the winglet cant angle can be changed from a planar configuration up to a vertical layout (including intermediate cant angles) and vice-versa. Therefore, the winglet can be adjusted 

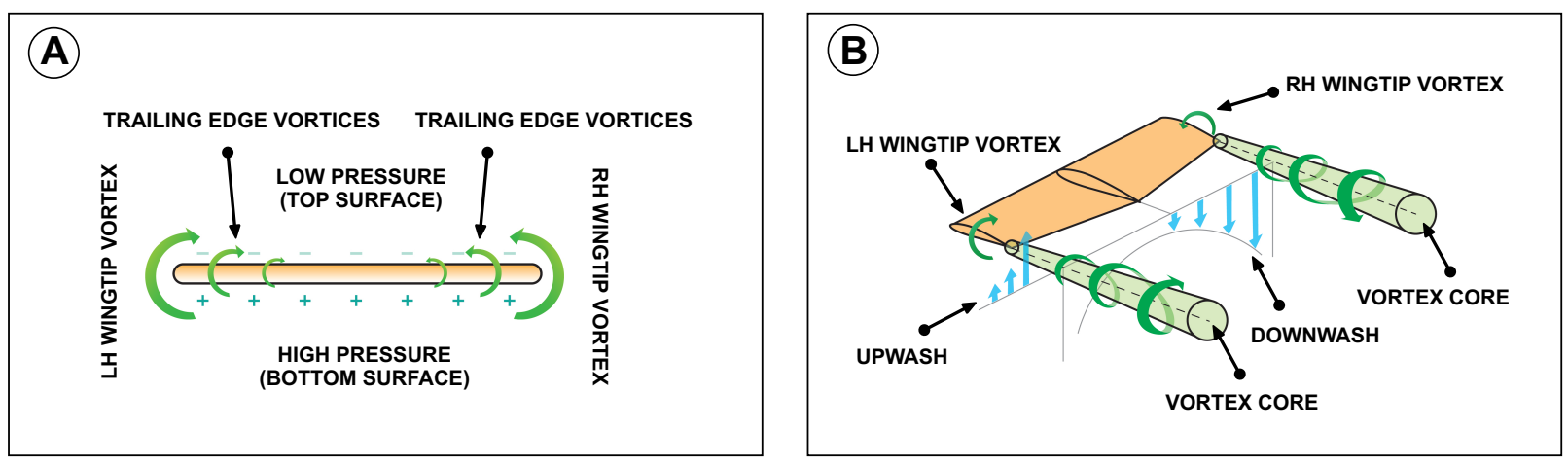

Figure 3: (A) Illustration of lift generation due to pressure imbalance and its associated trailing edge and wingtip vortices. (B) Illustration of wingtip vortices rotation and the associated downwash and upwash.

at different flight conditions to get the best lift-induced drag reduction for the given flight phase; or it can be kept in the vertical position while in ground so that it reduces wingspan while meeting gate and runaway clearance; or it can act as a load alleviation mechanism where in the case of gusts or strong sideslip velocities, the winglet can adjust itself, so it reduces the bending moment on the wing and the device itself. Similar solutions have been already proposed, but most of them focused on the use of shape memory alloy materials 2021222 2312425), foldable wings during

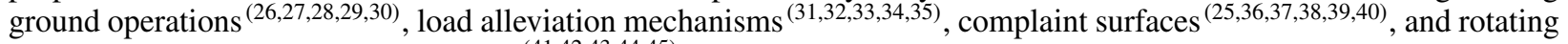
systems for mitigating wingtip vortices $\frac{[41 / 42 / 43|44| 45]}{\text {; }}$; but just a few of them have addressed variable cant angle winglets for drag reduction while flying $\frac{(41 / 47 / 48 / 49)}{\text {. }}$

The wing used in this study is the Onera M6 wing ${ }^{[5051]}$, with a variable cant angle winglet installed, and we conduct the study at two Mach numbers ( $M a=0.3$ and $M a=0.8395)$ and different angle-of-attack values. Thus, we aim at covering take-off, climb, approach, descent, and cruise conditions. The concept presented hereafter represents an innovative approach that the authors' hope holds potential to realize the goal of drag reduction to directly address the global challenge of improving aircraft fuel efficiency and reduce pollutant emissions, as highlighted in the reports ACARE - European aeronautics: A vision for 2020 $\frac{52 \sqrt{52}}{}$ and ACARE - Flightpath 2050: Europe's vision for aviation 53 .

\section{A brief review of lift-induced drag and its reduction using winglets}

Finite span wings generate lift due to the pressure imbalance between the bottom surface (high pressure) and the top surface (low pressure), as illustrated in figure 3 However, as a byproduct of this pressure differential, cross flow components of the velocity are generated (which are unavoidable but can be mitigated). The higher pressure air under the wing flows around the wingtips and tries to displace the lower pressure air on the top of the wing. This motion generates a trailing edge vortex, and at the wingtips, where the flow curls, large vortices are formed. This flow around the wingtips is sketched in figure 3 . These structures are referred to as wingtip vortices, and high velocities and low pressure exist at their cores. These vortices (trailing edge vortices and wingtip vortices), produce a downward flow in the neighborhood of the wing, known as the downwash and is denoted with the letter $w$ in figure 4 . The downwash interacts with the free-stream velocity to induce a local relative wind deflected downward in the vicinity of each airfoil section of the wing, as sketched in figure 4. The presence of the downwash reduces the angle-of-attack that each section of the wing effectively sees, and it creates a component of drag, the lift-induced drag, as it will be explained hereafter.

In figure 4 , the angle between the airfoil chord line and the direction of the undisturbed free-stream $V_{\infty}$ is the angleof-attack $A O A$, which we will call geometric $A O A$. In this figure, the local relative wind is inclined downward due to the downwash $w$, which gives rise to the induced angle-of-attack or $A O A_{\text {ind }}$. Therefore, the $A O A$ actually seen by the local airfoil section is the angle between the chord line and the local relative wind, or the effective angle-of-attack $A O A_{\text {eff }}$ defined as $A O A_{\text {eff }}=A O A-A O A_{\text {ind }}$. Even if the wind is at a geometric $A O A$, the local airfoil section always sees a smaller angle. This variation of the local $A O A$ is more pronounced towards the wingtips, where the downwash is stronger. Recall that the lift force is perpendicular to the local relative wind. In the presence of the downwash, the local lift vector is inclined by the angle $A O A_{\text {ind }}$, as shown in figure 4. As it can be seen in this figure, there is a component of the local lift vector in the direction of the undisturbed free-stream; that is, drag is created by the presence of the downwash. This drag is what we call lift-induced drag and is an unavoidable consequence of lift generation in finite span wings. 


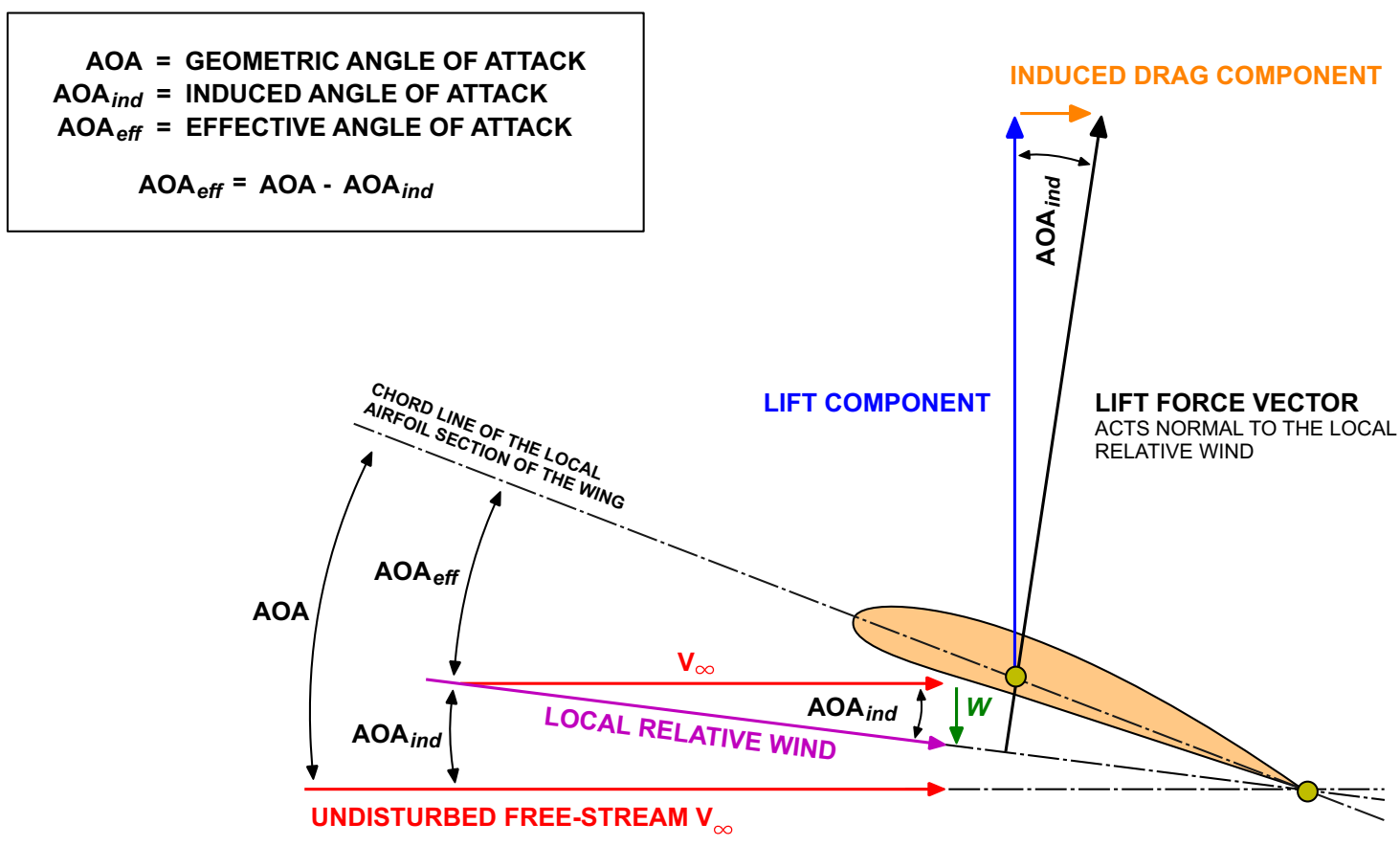

Figure 4: Illustration of lift-induced drag due to downwash.

A scenario similar to that of the downwash of the wing can be found at the winglets. Consider a section of the winglet as illustrated in figure 5. At the winglets the tip vortex is rolling up, therefore is generating a sidewash which induces a velocity component pointing towards the fuselage. As for the wings, the induced velocity component will create a local relative wind that will tilt the local lift vector, and for well-designed winglets the force component parallel to the undisturbed free-stream will point forward, therefore generating thrust (in analogy to sails in a sail boat). As a consequence, the thrust generated by the winglet counteracts any skin-friction and interference drag produced by the winglet itself. A similar analysis can be done for winglets bent downwards where the induced velocity is pointing outward, but operational requirements and ground clearances favor winglets bent upwards ${ }^{[54]}$.

Well-designed winglets will reduce the trailing vortex strength (hence the wingtip vortex) and the average wing downwash by modifying the pressure distribution (which is related to the spanwise lift distribution), and shifting the shed vorticity away from the wing plane (as sketched in figure 6). They will also counteract the skin friction and interference drag of the winglets by generating a thrust force induced by the sidewash ${ }^{[2 \mid 12[54}$. All this translate into less total drag due to the reduction of lift-induced drag and the parasite drag generated by the winglet.

\section{Wing model, computational domain, boundary conditions, and initial conditions}

The wing model used in this study is the Onera M6, as described in references $\sqrt{50 \mid 51)}$. To model the variable cant angle winglet, an extension to the baseline Onera M6 wing was added (as shown in figure 7). Then, the cant angle is modeled by adding a small curvature radius at the wingtip join with the winglet, in such a way as to guarantee a smooth transition between the wing and the winglet (as illustrated in figure 8). The winglet span used in this study corresponds to a $20 \%$ of the wingspan of the baseline wing. This value was chosen on the basis of previous studies $\frac{(16 / 12|55| 56|57| 58}{16}$, where the authors suggest the use of winglet span values between $10 \%$ to $20 \%$ of the wingspan. Additionally, we also studied the influence of the winglet sweep angle on the aerodynamic performance of the wing, where the sweep angle is defined as illustrated in figure 9. In table 1, we report the cant angles, sweep angles, and angle-of-attack values used in this study. As a guideline, in table 2 we report the wetted area of each wing used. Lastly, in table 3 , we report the values of the relative wingspan reduction in reference to the wing with winglet at cant angle $0^{\circ}$.

In figure 10, a sketch of the computational domain and the boundary conditions layout is shown. The far-field boundary in this figure corresponds to a Dirichlet type boundary condition and the outflow to a Neumann type boundary condition. The boundaries were placed far enough of the wing surface so there are no significant gradients normal to the surface 


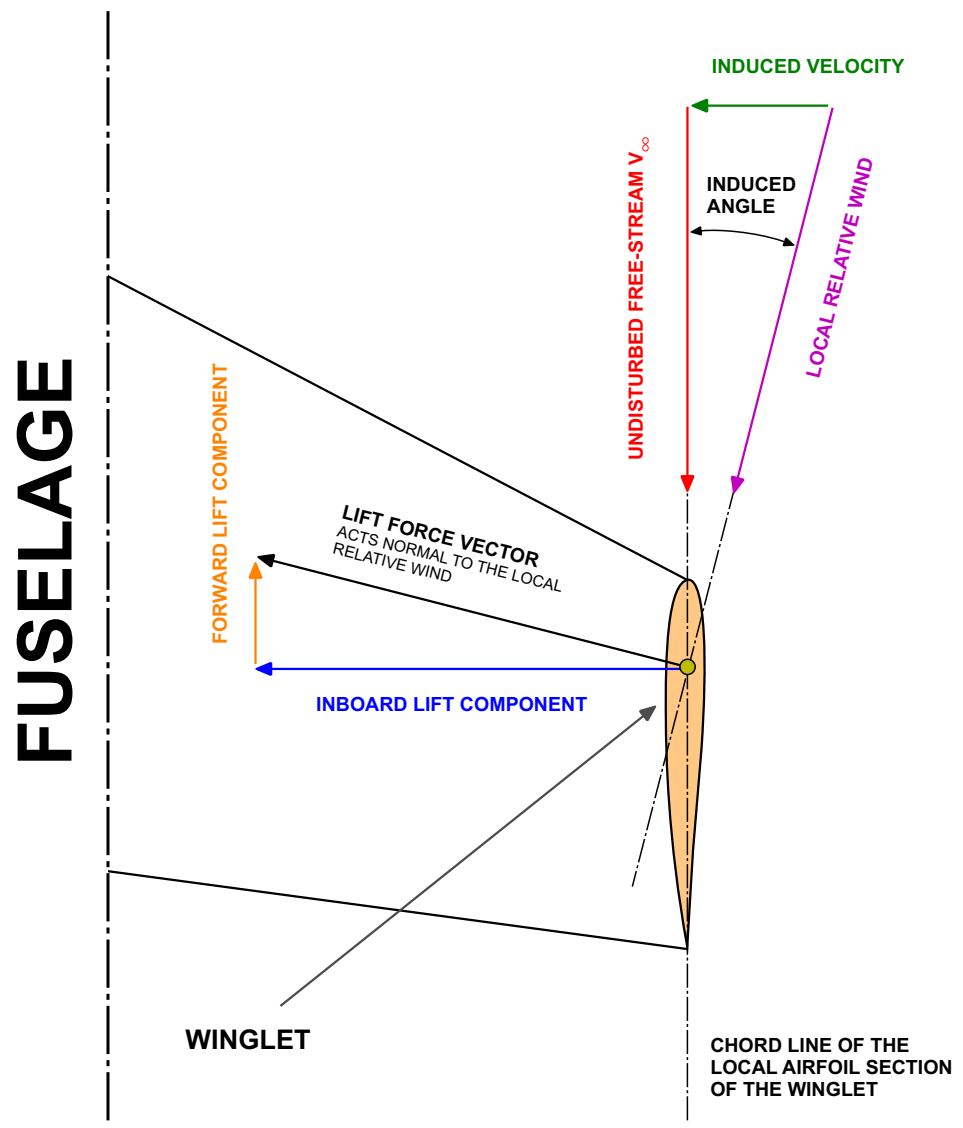

Figure 5: Illustration of forces generated at the winglets. Notice that for well-designed winglets there is a generation of thrust that counteracts skin friction and interference drag effects.

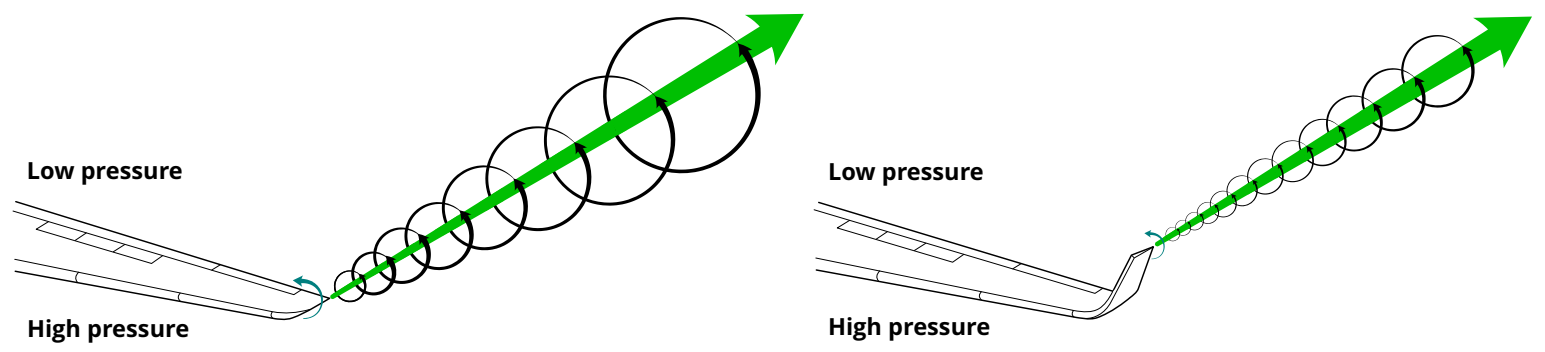

Figure 6: Wingtip vortices. Left image: wing with no winglet, in this wing a larger and stronger vortex is shed, resulting in more lift-induced drag. Right image: wing with winglet, in this wing a narrower and less intense vortex is shed, resulting in lower lift-induced drag. Also, the vortex is shifted away from the wing plane occurring in lower downwash.

Table 1: Design space explored in this study. All the angles are defined in degrees.

Winglet cant angle Winglet sweep angle Angle-of-attack at $M a=0.3$ Angle-of-attack at $M a=0.8395$
$0,15,45,80$

$30,45,60$

0-20 (spaced at intervals of 2)

0-10 (spaced at intervals of 2) 
A PREPRINT

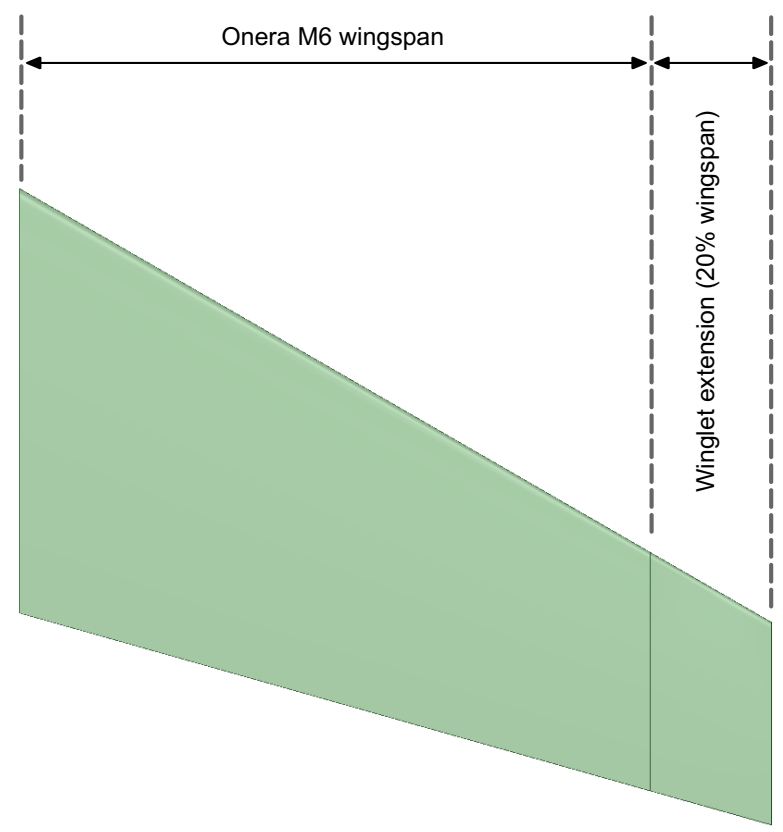

Figure 7: Wing and winglet extension. The winglet span used in this study corresponds to a $20 \%$ of the wing span of the original Onera M6 wing.
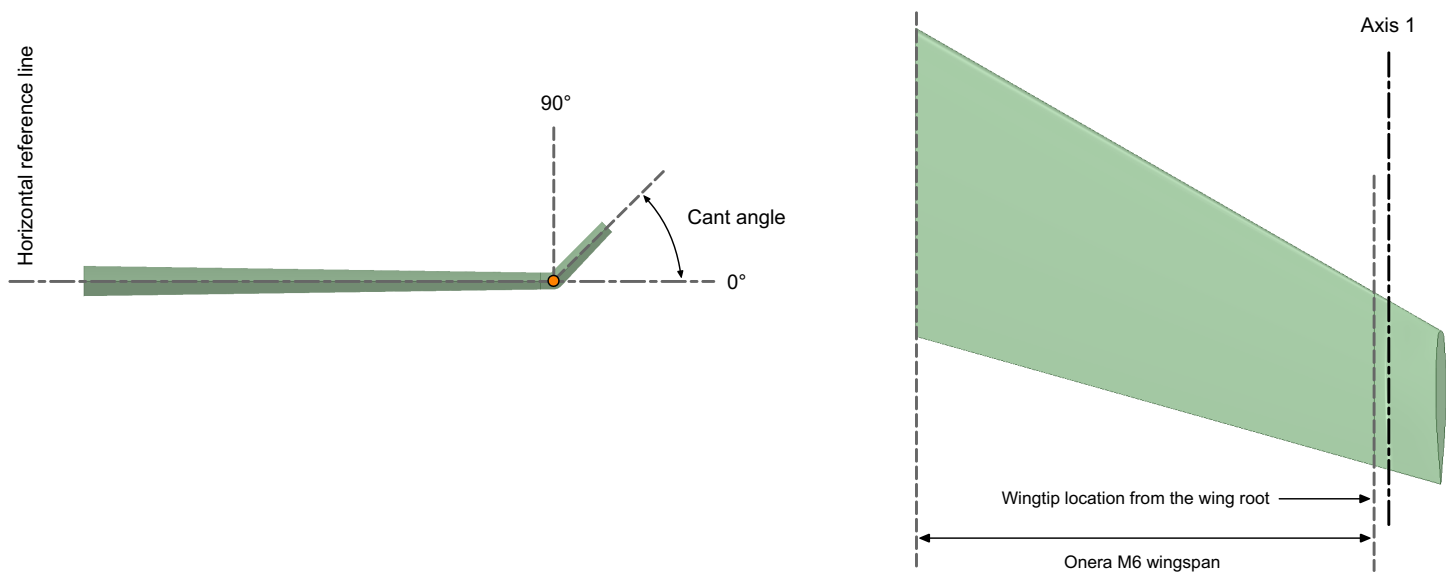

Figure 8: Winglet cant angle definition (left image). The winglet extension is bent upwards about the axis 1 (right image). This axis is located $40 \mathrm{~mm}$ away from the wingtip. For all cases studied, the curvature radius is no more than $30 \mathrm{~mm}$. 

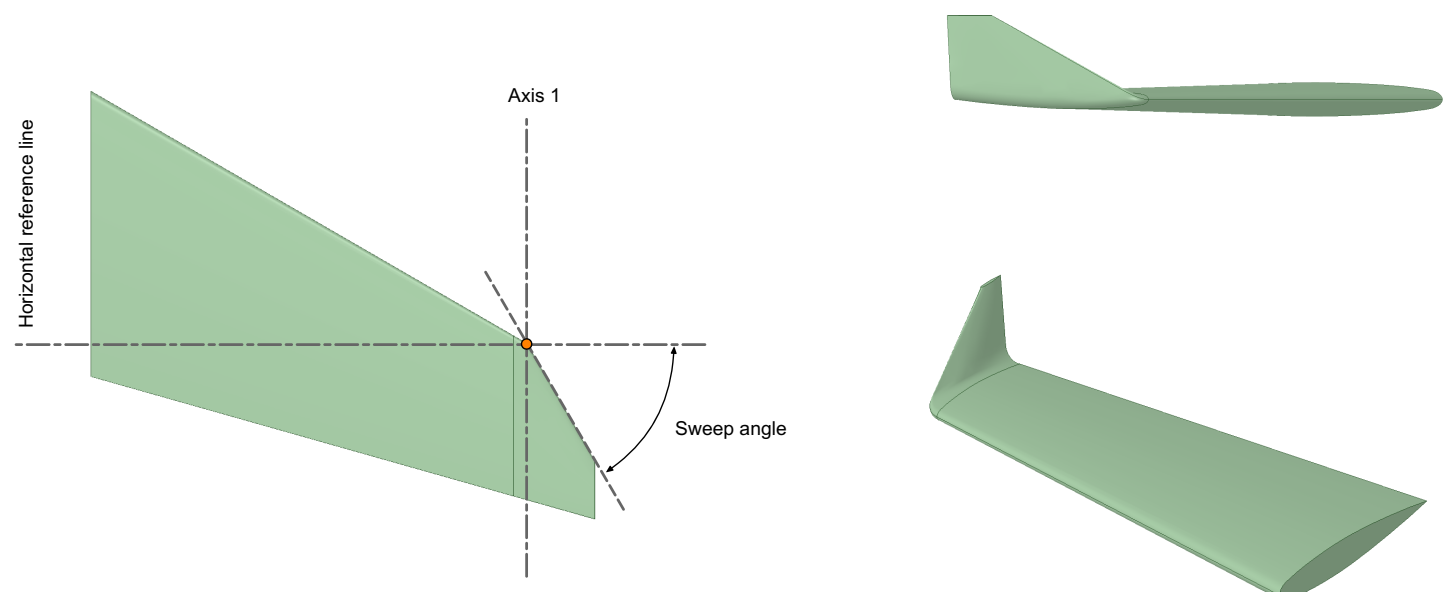

Figure 9: Left image: winglet sweep angle definition. Right image: winglet geometry corresponding to a cant angle of $80^{\circ}$ and a sweep angle of $60^{\circ}$.
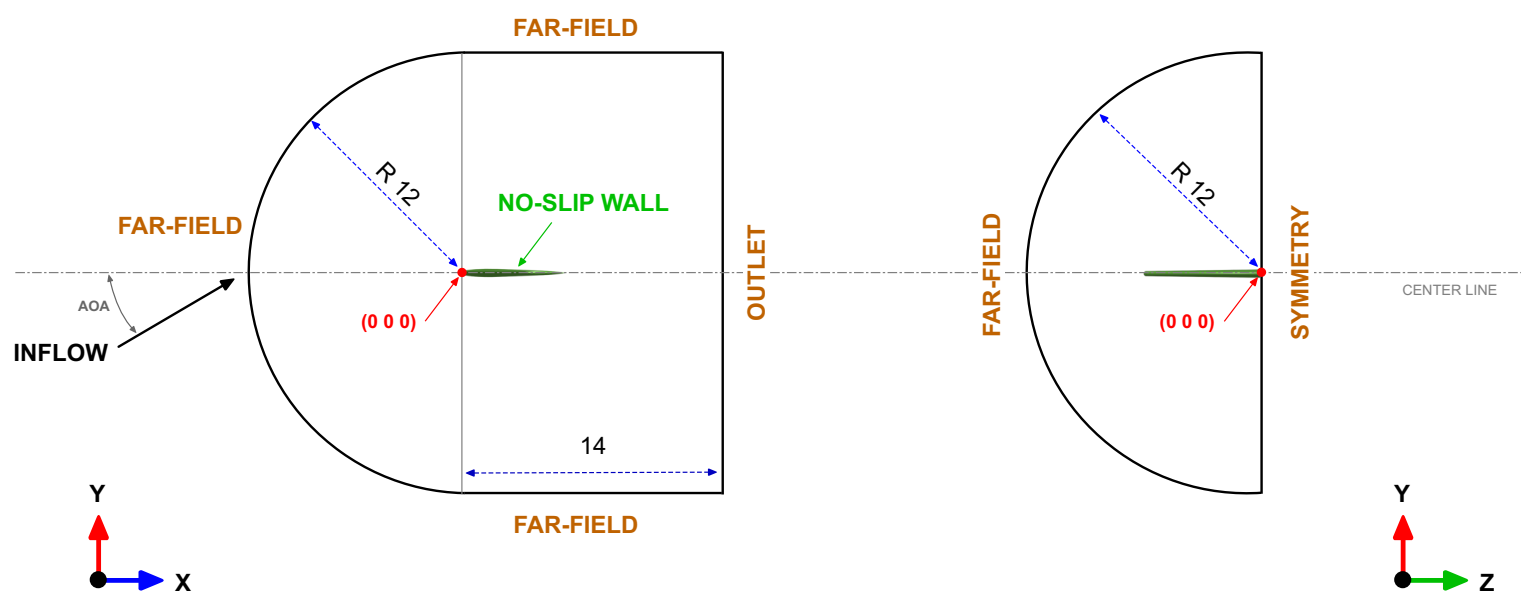

Figure 10: Computational domain and boundary conditions (all dimensions are in meters). The illustration is not to scale.

boundaries. The wing was modeled as a no-slip wall, where we used continuous wall function boundary conditions for the turbulence variables. In all cases, the average distance from the wing surface to the first cell center off the surface is approximately four viscous wall units $\left(y^{+} \approx 4\right)$.

A hybrid mesh was used for all the simulations, with prismatic cells close to the wing surface and tetrahedral and polyhedral cells for the rest of the domain. Also, in the vicinity of the wing and wake region, we added a refinement region with uniform cell size (as illustrated in figure 11). A typical mesh is made up of approximately 3.6 to 4.1 million cells, depending on the cant and sweep angle.

The lift force $L$ and drag force $D$ are calculated by integrating the pressure and wall-shear stresses over the wing surface; then, the lift coefficient $C_{L}$ and drag coefficient $C_{D}$ are computed as follows:

$$
C_{L}=\frac{L}{0.5 \times \rho \times V_{\infty}^{2} \times S_{r e f}} \quad \text { and } \quad C_{D}=\frac{D}{0.5 \times \rho \times V_{\infty}^{2} \times S_{r e f}}
$$

where $\rho$ is the air density, $V_{\infty}$ the free-stream velocity, and $S_{r e f}$ is the wing reference area. 


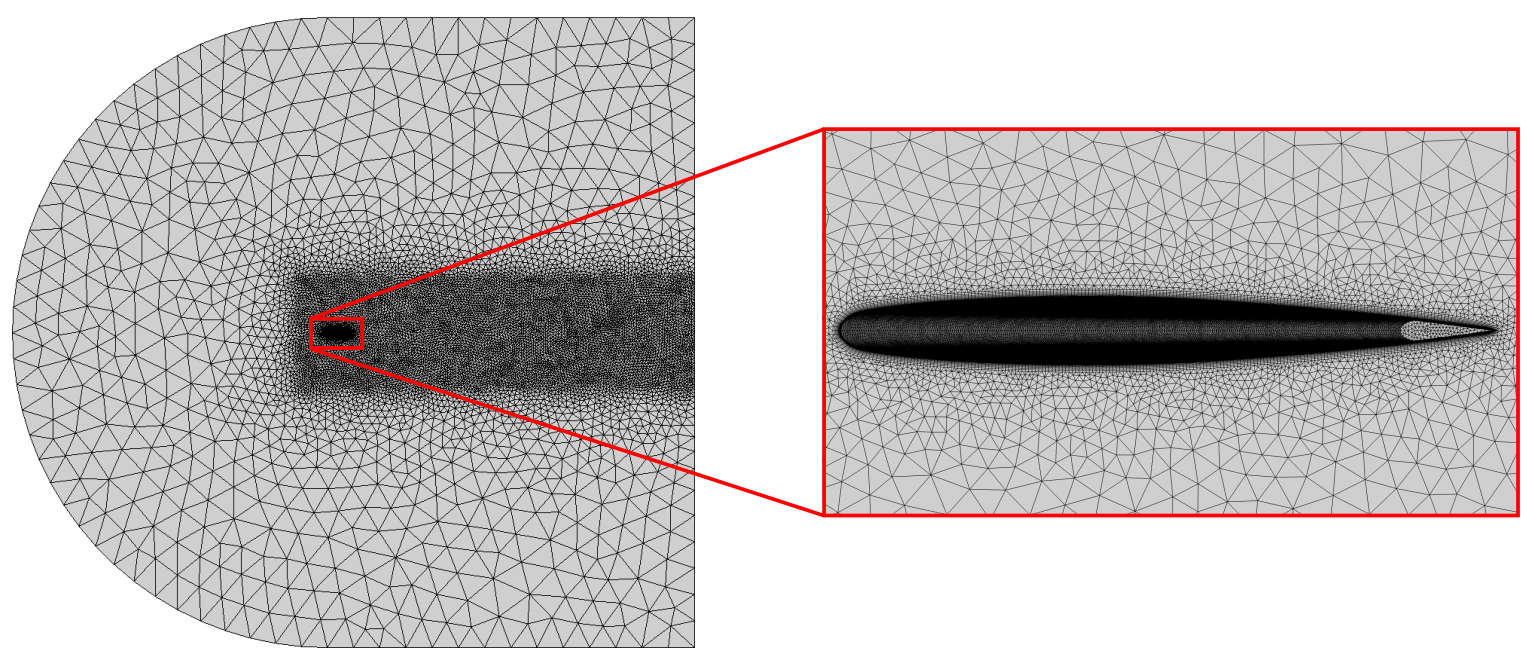

Figure 11: Domain mesh. The mesh is visualized in the symmetry plane and wing surface.

Table 2: Wetted area of each wing used in this study.

\section{Wing}

Baseline wing (original Onera M6 wing)

Wing with winglet - Winglet sweep angle $30^{\circ}$

Wing with winglet - Winglet sweep angle $45^{\circ}$

Wing with winglet - Winglet sweep angle $60^{\circ}$

Reference area $\left(\mathrm{m}^{2}\right)$
1.5952
1.7881
1.7694
1.7388

Finally, the $A O A$ was changed by adjusting the incidence angle value of the inlet velocity, and all forces were computed in the reference system aligned with the inlet velocity. All the computations were initialized using free-stream values and the incoming flow is characterized by a turbulence intensity value equal to $5.0 \%$. All the turbulence variables were initialized following the guidelines given in references ${ }^{[59|60| 61)}$.

\section{Numerical method and validation}

The compressible Reynolds-Averaged Navier-Stokes (RANS) equations are solved by using the finite volume solver Ansys Fluent ${ }^{\mid 62)}$. The cell-centered values of the variables are interpolated at the face locations using a second-order centered difference scheme for the diffusive terms. The convective terms are discretized by means of the second-order upwind scheme ${ }^{633}$. For computing the gradients at cell-centers, the least squares cell-based reconstruction method is used. In order to prevent spurious oscillations, a multi-dimensional gradient limiter is used ${ }^{64}$. The pressure-velocity coupling is achieved by means of the SIMPLE algorithm ${ }^{\sqrt{65 \mid 66}}$, where we used the default under-relaxation parameters. As the solution takes place in collocated meshes, the Rhie-Chow interpolation scheme is used to prevent the pressure checkerboard instability. For turbulence modeling, the $\kappa-\omega$ SST model is used ${ }^{[59] 60 \mid 61]}$. The turbulence quantities, namely, turbulent kinetic energy $\kappa$ and specific dissipation rate $\omega$, are discretized using the same scheme as for the convective terms.

Before proceeding to the parametric study, we assessed the accuracy of the numerical scheme and mesh resolution used. In this validation study, we compare the numerical solution outcome against the data of the physical experiments at the

Table 3: Relative wingspan reduction in reference to the wing with winglet at cant angle $0^{\circ}$.

\section{Wing}

Wing with winglet at cant angle $0^{\circ}$

Wing with winglet at cant angle $15^{\circ}$

Wing with winglet at cant angle $45^{\circ}$

Wing with winglet at cant angle $80^{\circ}$

Baseline wing (original Onera M6 wing)

\section{Wingspan reduction (\%)}

$$
\begin{aligned}
& -\bar{\sim} \\
\approx & 4.5 \\
\approx & 11.2 \\
\approx & 16.2
\end{aligned}
$$


Table 4: Comparison of $C_{L}$ and $C_{D}$ obtained with different solvers (data taken from reference ${ }^{\sqrt[51]{1}}$ ). The comparison is done for meshes with similar cell count.

$\begin{array}{lcc}\text { Solver - Mesh type } & C_{L} & C_{D} \\ \text { CFL3D - Structured mesh } & 0.2661 & 0.0173 \\ \text { USM3D - Tetrahedral mesh } & 0.2649 & 0.0186 \\ \text { FUN3D - Prismatic mesh } & 0.2659 & 0.0172 \\ \text { Current solution - Hybrid mesh (tetrahedra + polyhedra + prisms) } & 0.2597 & 0.0188\end{array}$

same operating conditions described by Schmitt and Charpin [50], that is, Reynolds number $\operatorname{Re}=11.72 \times 10^{6}$, Mach number $M a=0.8395$, and angle-of-attack equal to $3.06^{\circ}$.

In figure 12 we plot the pressure coefficient $C p=\left(p-p_{\infty}\right) /\left(0.5 \rho V_{\infty}^{2}\right)$ values obtained from the numerical simulations against the experimental values at different wingspan locations. As it can be seen, the numerical solution shows a similar trend to the $C p$ distribution obtained in the wind tunnel experiments. Additionally, in table 4 we compare the $C_{L}$ and $C_{D}$ values against the values obtained using different CFD solvers ${ }^{[51]}$. In this table, we can evidence a fairly good match among all solvers, even if the meshes and solution methods are different. In this validation study, the reference area used for $C_{L}$ and $C_{D}$ computations is equal to $0.7532 \mathrm{~m}^{2}$, as described in reference ${ }^{[50]}$.

As a side note, the turbulence model used in reference ${ }^{\sqrt{51})}$ was the Spalart-Allmaras whereas in this study we used the $\kappa-\omega$ SST. Additionally, we did not model the rounded wingtip as described in references ${ }^{[50[51]}$, so these two factors might represent a source of uncertainty, which however we deem to be negligible for the purposes of this study. Based on the results presented, we can state that the selected numerical scheme, turbulence model, and mesh resolution are adequate to resolve the physics involved.

Finally, during this study air was modeled using the equation of state for ideal gases, and the dynamic viscosity was computed using the Sutherland model. It is worth mentioning that the original Onera M6 wing report ${ }^{50]}$, does not give specific details about the working conditions; therefore, we assumed air at sea-level and at $300^{\circ} K$. The temperature was determined by using an iterative procedure so that $R e$ and $M a$ conditions are matched, together with the equation of state $p=\rho R T$, the speed of sound relationship $a=\sqrt{\gamma R T}$, and the Sutherland dynamic viscosity equation $\mu=\left(C_{1} T^{3 / 2}\right) /\left(T+C_{2}\right)$ (where $T$ is the temperature given in degrees Kelvin, and $C_{1}$ and $C_{2}$ are the coefficients of the Sutherland model). While it is difficult to determine if the operating conditions used in the simulations correspond to the same conditions of the wind tunnel experiments, the assumptions taken in this study appear to be justified given the good agreement between the physical experiments and the numerical simulations.

\section{Numerical results and discussion}

In this section, we discuss the results of the aerodynamic performance of the wing with variable cant angle winglet in reference to the baseline wing (original Onera M6 wing). An extensive campaign of simulations was carried out, as per the design space listed in table 1. For all cases, the reference area used for $C_{L}$ and $C_{D}$ computations is equal to $1.0 \mathrm{~m}^{2}$. The computations were carried out in parallel using 16 cores, and each simulation took approximately 4 to 6 hours to convergence to a level where the forces showed either a non-oscillatory behavior or a periodic behavior.

\subsection{Aerodynamic performance at high Mach number $-M a=0.8395$}

Hereafter, we discuss the results at Mach number equal to 0.8395 , which might corresponds to a typical velocity encountered at cruise conditions on subsonic civil transport aircraft. We explore $A O A$ values up to $10^{\circ}$, which correspond to the values of $A O A$ that might be encountered during cruise and change of cruise level on medium and long-range subsonic transport aircraft.

Let us use the drag polars plotted in figures 13 . 15 to study the influence of the winglet cant angle and sweep angle on the aerodynamic performance of the wing. By looking at these figures, we can notice a strong influence of the sweep angle on the drag polars, that is, as we increase the sweep angle, the drag polar curves are shifted upward, and this trend contributes to an improvement of the aerodynamic performance, i.e., for the same lift coefficient less drag is produced. For instance, in figure 13 (winglet sweep angle $30^{\circ}$ ) we can see that when the winglet cant angle is equal to $80^{\circ}$ the overall performance of the wing is worse than that of the baseline wing, or in other words, for a given value of $C_{L}$ the wing with winglet will produce more drag. However, as we increase the sweep angle, the drag polar is slightly shifted upwards, so eventually, the wing with winglet will produce less drag for a given $C_{L}$ value when compared to the baseline wing. This situation is illustrated in figures 14 and 15 , where for example, for a value of $C_{L}=0.3$ all the configurations studied will produce less drag than the baseline wing. 
$20 \%$ wingspan

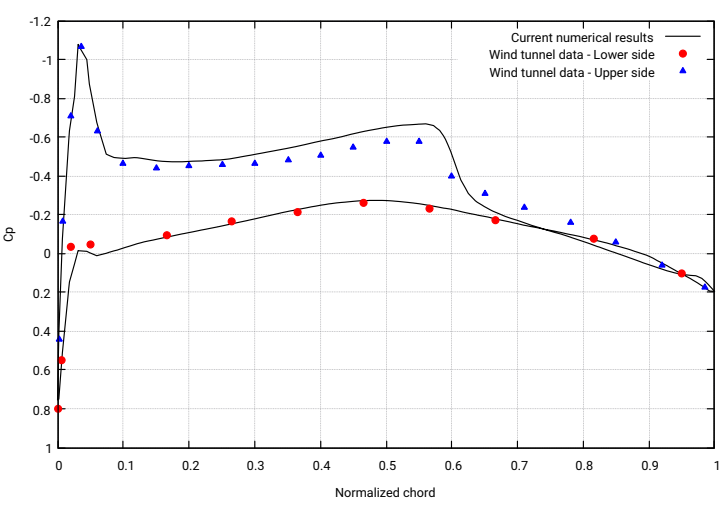

$65 \%$ wingspan

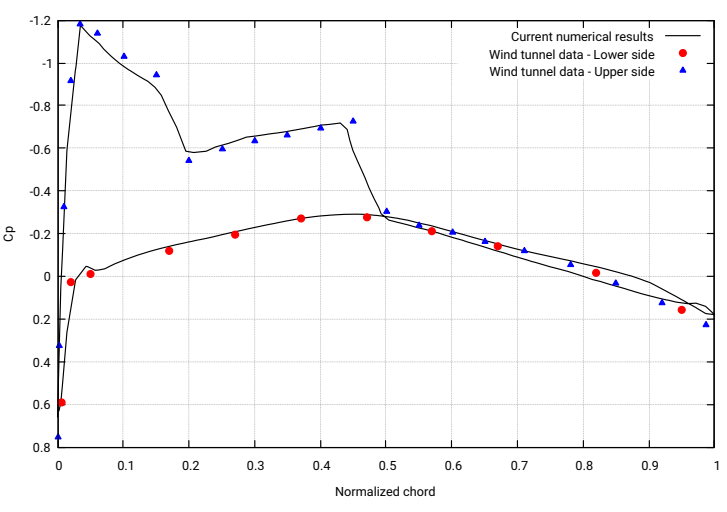

$90 \%$ wingspan

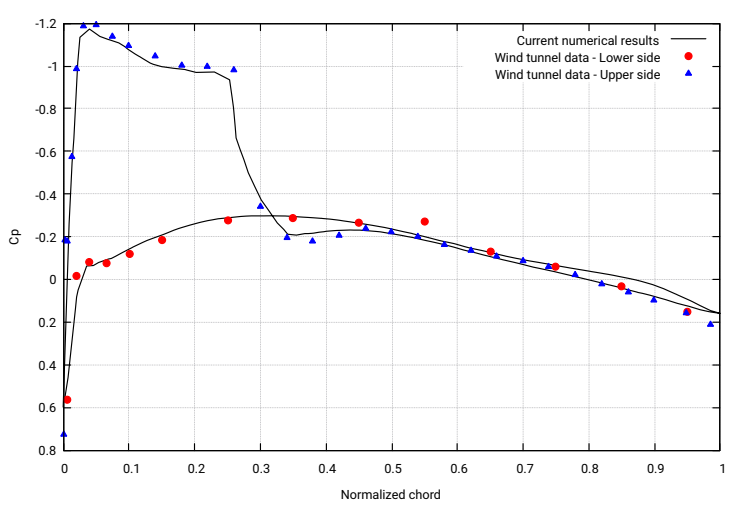

$44 \%$ wingspan

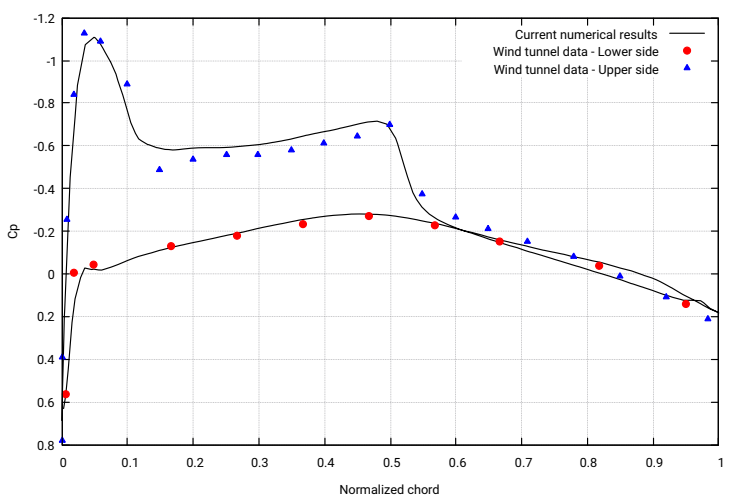

$80 \%$ wingspan

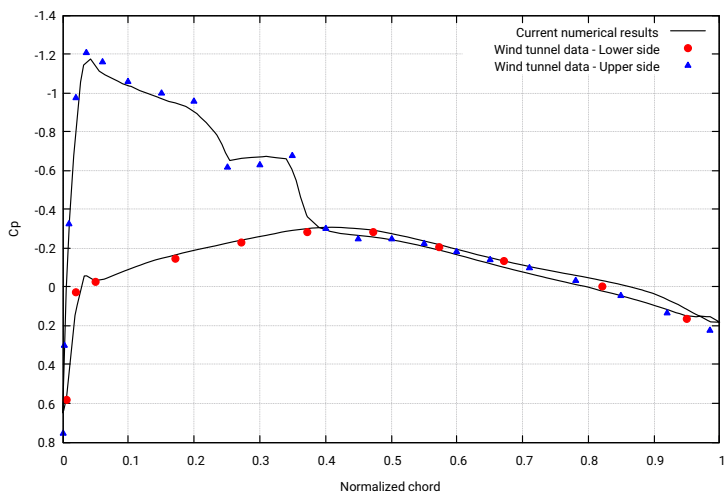

$95 \%$ wingspan

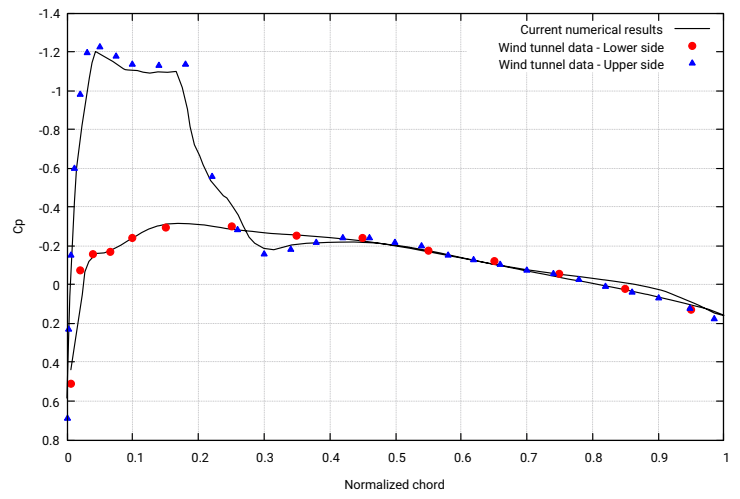

Figure 12: Plot of the pressure coefficient $C p$ on the wing surface at different sections. Comparison of numerical and experimental results. 


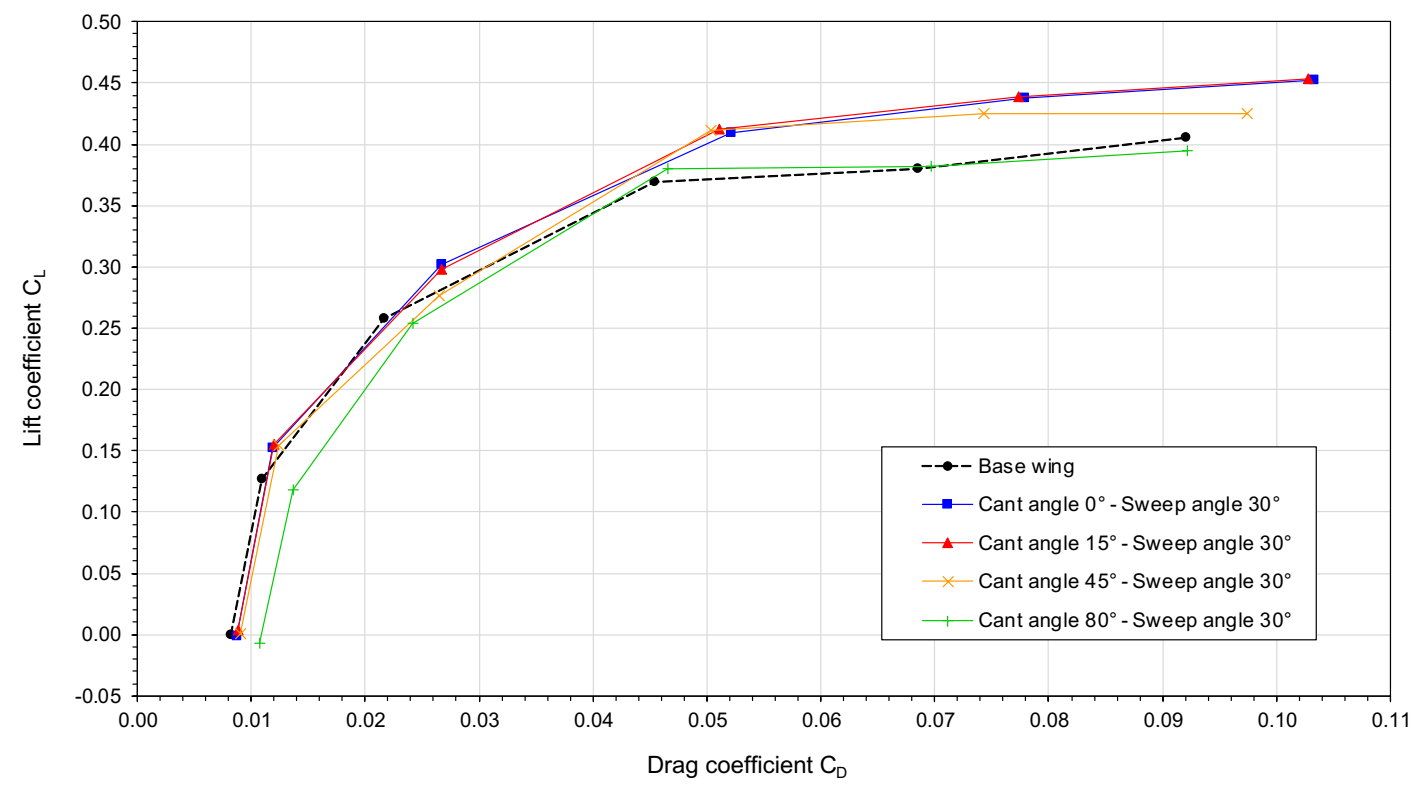

Figure 13: Drag polar at Mach number 0.8395, sweep angle $30^{\circ}$ and different values of cant angle.

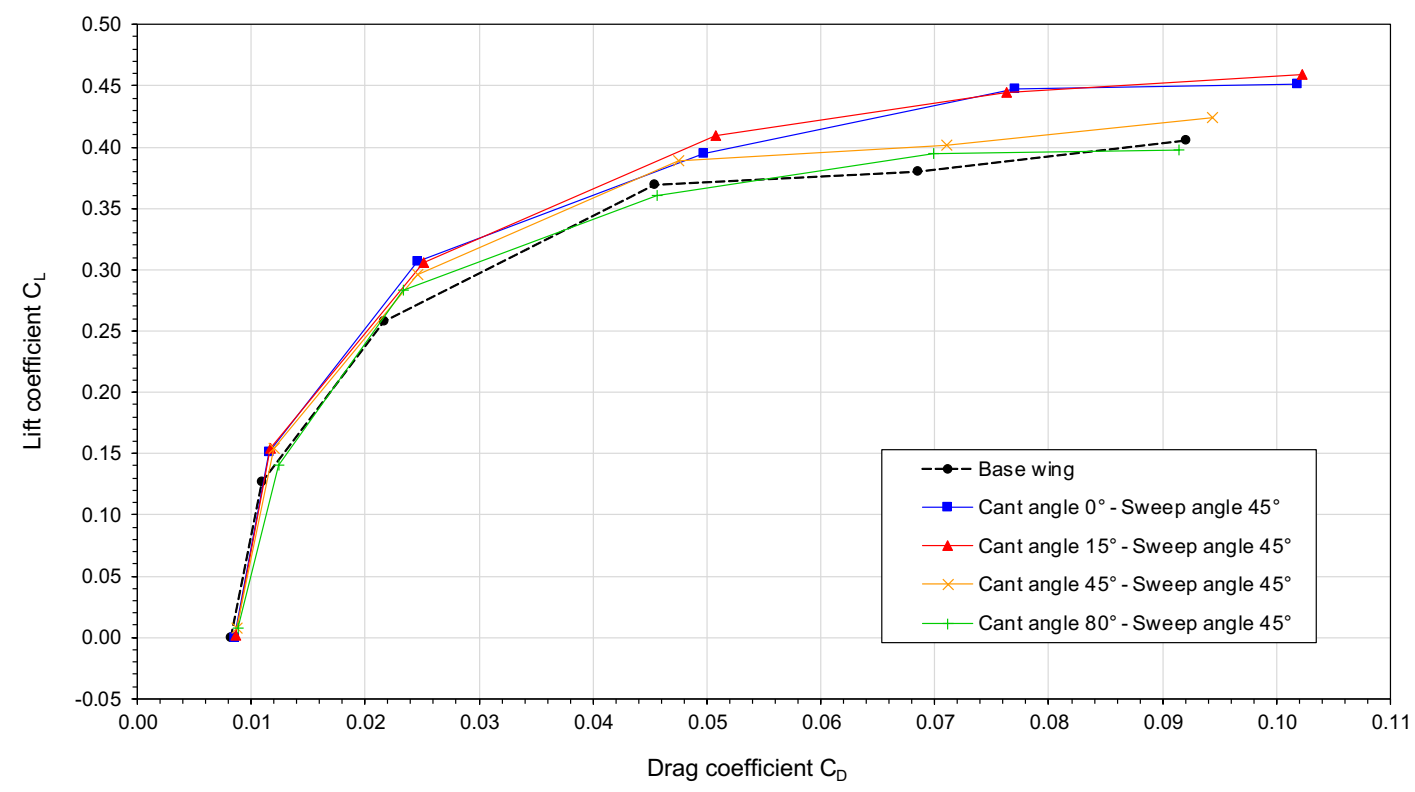

Figure 14: Drag polar at Mach number 0.8395, sweep angle $45^{\circ}$ and different values of cant angle 


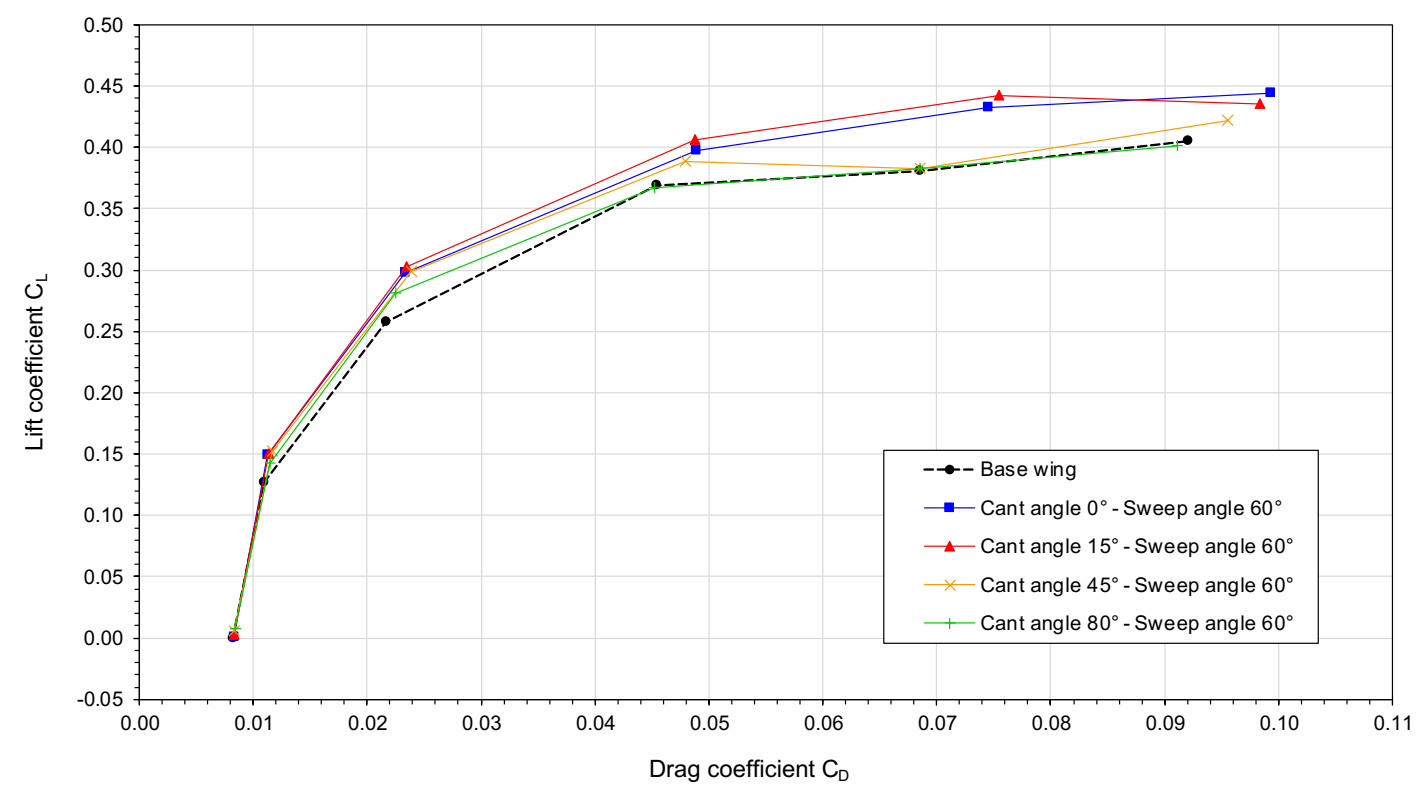

Figure 15: Drag polar at Mach number 0.8395, sweep angle $60^{\circ}$ and different values of cant angle

Table 5: Wing-winglet wave drag ratio at $A O A 2^{\circ}$.

$\begin{array}{ccc}\text { Winglet sweep angle }\left({ }^{\circ}\right) & \text { Winglet cant angle }\left(^{\circ}\right) & \text { Wing-winglet wave drag ratio } \\ 30 & 80 & 1.0 \\ 60 & 80 & 0.8515 \\ 60 & 45 & 0.8195 \\ 60 & 15 & 0.8250 \\ 60 & 0 & 0.8481 \\ & \text { Baseline wing } & \end{array}$

The effect of the sweep angle on the aerodynamic performance can be explained by the fact that at higher sweep angles less skin friction drag and interference drag is produced. Another factor that contributes to the drag reduction at high Mach number is the impact of the winglet sweep angle on the wave drag. This particular wing is known to generate a shock wave system on the wing surface; this shock wave interacts with the winglet (as depicted in figures 16 and 17), therefore increasing the wave drag.

In figure 16, we illustrate the wing-winglet shock wave interaction (WWSWI) for two different winglet sweep angles and a cant angle of $80^{\circ}$, where the shock wave region was computed using the criterion of Lovely and Haimes 67 . In this figure, we can observe that for larger sweep angles the shock wave intensity is reduced. Hence, as for wings designed for high-speed, the sweep-back angle have a positive effect in reducing the wave drag of the winglets. In figure 17, we show the WWSWI but this time for a sweep angle of $60^{\circ}$ and three different cant angles. In this figure, we can observe that for large cant angle values the WWSWI is stronger, thus the wave drag is larger. It is worth mentioning that the WWSWI might also cause additional detrimental phenomena, such as boundary layer separation and buffeting.

In table 5, we quantify the wave drag ratio for five representative configurations at $A O A 2^{\circ}$. In this table, the wave drag ratio is calculated as the ratio of the wave drag of the given wing-winglet configuration and the wave drag of the configuration with a winglet sweep angle of $30^{\circ}$ and a cant angle of $80^{\circ}$ (the arrangement that generates the largest wave drag and parasite drag). In all cases, the wave drag was computed using the drag decomposition method described by Destarac and van der Vooren ${ }^{688}$. From these quantitative results, we can see the influence of the cant angle on the wave drag, that is, as we decrease the cant angle the wave drag decreases. We can also note that as we increase the winglet sweep angle, the wave drag is reduced. It is worth noting that the increment of the wave drag due to the winglet addition is almost proportional to the wingspan increment of the baseline wing (20\%).

Let us now study the influence of the cant angle on the aerodynamic performance of the wing, and always in reference to figures 13 15. In these figures and for the same winglet sweep angle values, we can evidence that low to moderate values 

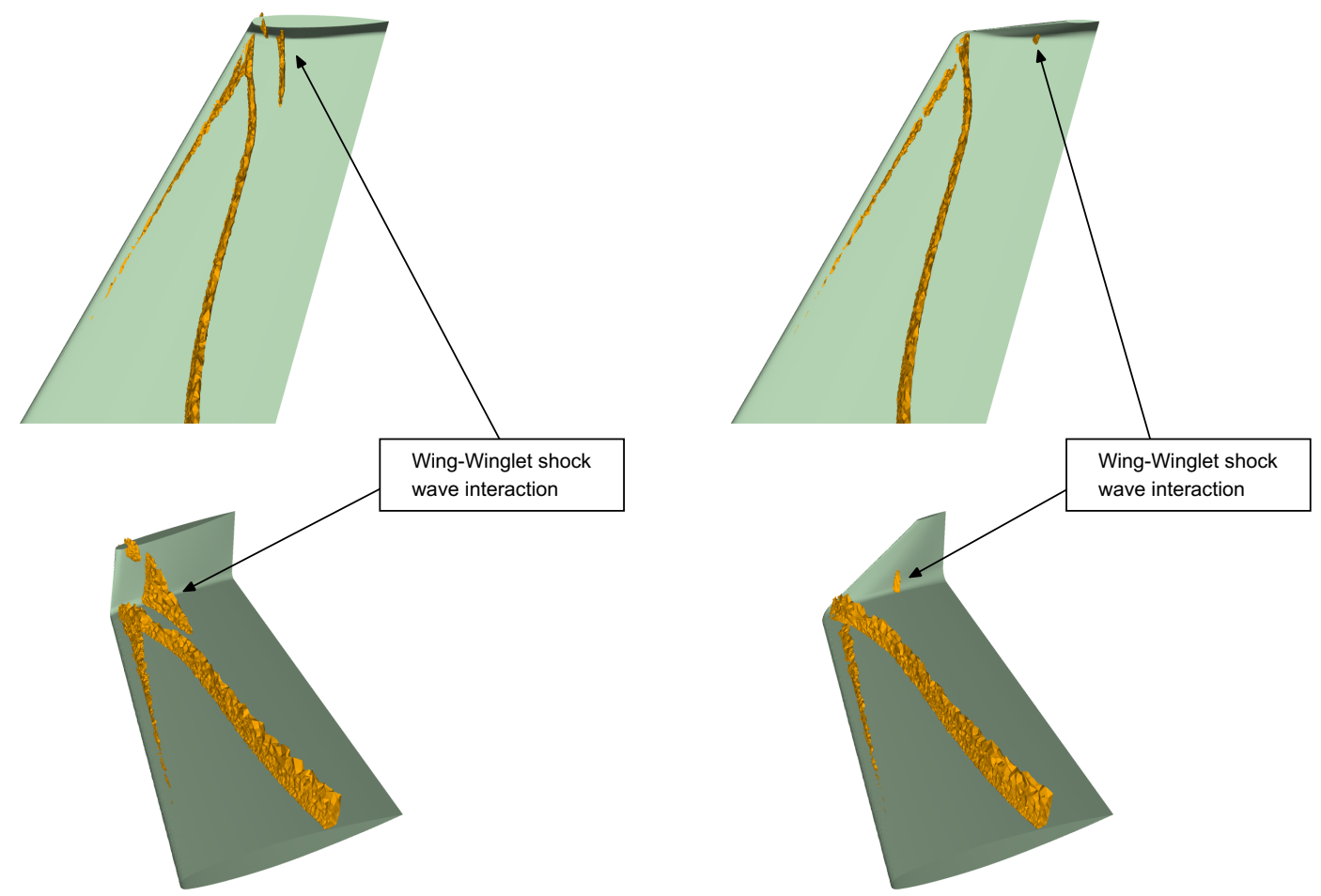

Figure 16: Shock wave system for $A O A 2^{\circ}$, winglet cant angle $80^{\circ}$ and two different values of winglet sweep angle. The left image corresponds to a winglet sweep angle of $30^{\circ}$ and the right image to a sweep angle of $60^{\circ}$. The shock wave region was computed using the criterion of Lovely and Haimes ${ }^{677}$.
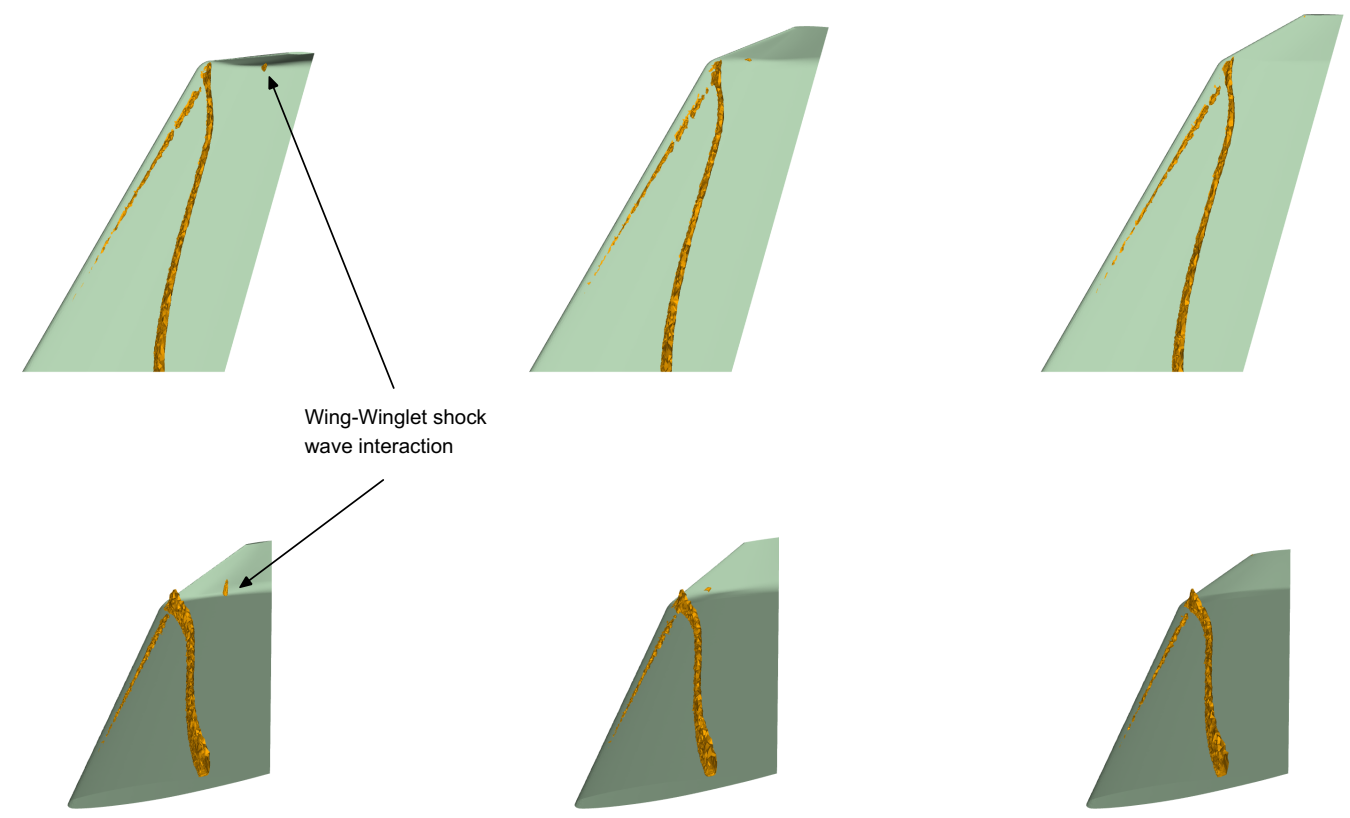

Figure 17: Shock wave system for $A O A 2^{\circ}$, winglet sweep angle $60^{\circ}$, and different values of winglet cant angle. The left image corresponds to a winglet cant angle of $80^{\circ}$, the middle image to a cant angle of $45^{\circ}$, and the right image to a cant angle of $15^{\circ}$. The shock wave region was computed using the criterion of Lovely and Haimes ${ }^{677}$. 
of cant angle $\left(0^{\circ}-45^{\circ}\right)$ have a minor effect on the drag polar curves at $A O A$ values less than $4^{\circ}$. On the other hand, for $A O A$ values higher than $4^{\circ}$ there is a tendency to shift the drag polar curves downwards, in particular for moderate to high values of cant angle $\left(45^{\circ}-80^{\circ}\right)$. This decrease in the aerodynamic performance is related to two factors, the superior parasite drag generated by the winglet at high cant angles and the reduction of the pressure differential towards the wingtips.

To understand the reason of the pressure differential reduction, let us take a look at figure 18 , where the pressure coefficient on the wing surface is displayed for a configuration with winglet sweep angle $60^{\circ}$ and four cant angles. In this figure, we can observe that as we increase the cant angle, the winglet will work as a wall that will reduce the pressure differential between the bottom and top surfaces of the wing. This reduction of the pressure differential, which is stronger towards the wingtip, is responsible for the decrement of the maximum $C_{L}$ and the slope of the lift curve. As we reduce the cant angle, the reduction in the pressure differential is lessened, therefore the maximum lift increases, as it can be confirmed in figure 19 . The winglet effect of reduction of the pressure differential also affects drag, as it can be seen in figure 20. But in this case, the reduction of the pressure differential has a positive impact by reducing the drag and the intensity of the wingtip vortices.

Let us quantify the minimum drag coefficient $C_{D_{\min }}$ in the drag polar plots depicted in figures 13 15. Hereafter, we compute the $C_{D_{\min }}$ percentage reduction (or increment) in reference to the baseline wing. For the wing with winglet sweep angle $30^{\circ}$ (figure 13 , the configuration with cant angle $80^{\circ}$ increases $C_{D_{\min }}$ by approximately $30 \%$, for cant angle $45^{\circ}$ the $C_{D_{\min }}$ is increased by $\approx 10 \%$, for cant angle $15^{\circ}$ the $C_{D_{\min }}$ is increased by $\approx 7.0 \%$, and for cant angle $0^{\circ}$ the $C_{D_{\min }}$ is increased by $\approx 4.0 \%$. If we now take a look at figure 14 (wing with winglet sweep angle $45^{\circ}$ ), the situation is slightly different. In this figure, the configurations with cant angles $0^{\circ}$ and $15^{\circ}$ increase $C_{D_{\min }}$ by about $4.0 \%$, for a cant angle of $45^{\circ}$ the $C_{D_{\min }}$ is increased $\approx 5.0 \%$, and the $C_{D_{\min }}$ of the wing with winglet cant angle $80^{\circ}$ is approximately $7.0 \%$ larger. Finally, in figure 15 (wing with winglet sweep angle $60^{\circ}$ ), the $C_{D_{\min }}$ of the wing with winglet cant angle $80^{\circ}$ is approximately $2.5 \%$ larger, whereas the $C_{D_{\min }}$ for the other cant angles is increased by about $1.0 \%$. These results clearly indicate that large cant angle values generate more parasite drag (possibly due to strong interference effects).

In the previous discussion, the reduction of $C_{D_{\min }}$ as the winglet sweep angle is increased, can be attributed to the fact that at higher sweep angles less skin friction drag and interference drag is produced. Also, the addition of the sweep angle to the winglet and the sidewash generated by the flow in the surroundings of the winglet, might modify the inboard lift force generated by the winglet (as depicted in figure 5, which contributes to reducing (or increasing) the $C_{D_{\min }}$. It is also important to note that in figure 15 . none of the configurations with winglet installed have a strong detrimental crossover point. In all cases plotted in this figure and for $A O A$ less than $2^{\circ}$, the wings with winglet generate little less drag, or the difference is negligible respect to the baseline wing. For $A O A$ larger than $2^{\circ}$ the difference in $C_{D}$ for the same $C_{L}$ is more evident.

To make a comprehensive treatment of how the variable cant angle winglets could improve the wing aerodynamic performance, let us compute the $C_{D}$ at three $C_{L}$ targets, namely, 0.1, 0.2, and 0.35. In this hypothetical situation, the $C_{L}$ targets could correspond to cruise conditions or $0.1<C_{L}<0.2$ (which corresponds to the maximum $C_{L} / C_{D}$ ratio) and cruise climb conditions or $C_{L}=0.35$ (which approximately corresponds to the maximum $C_{L}^{2} / C_{D}$ ratio and is on the limit of the linear regime of the lift curve). These results are summarized in tables $6 \mid 8$ and as it can be seen, for cruise conditions $\left(0.1<C_{L}<0.2\right)$ the largest drag reduction is obtained at cant angles between $0^{\circ}$ and $45^{\circ}$, this suggest that the winglets could be adjusted in flight according to fuel consumption. For cruise climb $\left(C_{L}=0.35\right)$, the best results are obtained at a cant angle value of $15^{\circ}$. However, values up to $80^{\circ}$ are also acceptable as they produce less drag for the same $C_{L}$.

These results show how winglets reduce the drag by artificially increasing the wingspan. The relative wingspan reduction is shown in table 3, by cross-referencing these values with the results shown in tables 6 8 , it can be seen that as we reduce the wingspan (by increasing the winglet cant angle), the aerodynamic performance is improved in reference to the baseline wing. In general, for cant angle $80^{\circ}$ the gains in drag reduction are not the same to those achieved by merely extending the wingspan by an amount equal to the winglet span (equivalent to a winglet configuration with cant angle $0^{\circ}$ ), but approximately half that amount. For the other cant angle values $\left(45^{\circ}\right.$ and $\left.15^{\circ}\right)$ the drag reduction is about the same amount or even larger. In addition, increasing the winglet cant angle does not add the extra wing root bending moment that would be encountered if the wingspan were simply increased by the span of the winglet, and this is a desirable benefit from the structural point of view.

For completeness, in figure 21 we plot the drag polars for fixed cant angles and different sweep angles. In this figure, we can better highlight the influence of the sweep angle on the aerodynamic performance. It is clear that as we increase the sweep angle the crossover point is shifted downwards, up to the point that the performance of the wing with winglets is better in the whole envelope of the drag polar. For the case with cant angle equal to $45^{\circ}$, the crossover point is located approximately between $2^{\circ}$ and $3^{\circ}$ of $A O A$ for all cases. For the cases with cant angles equal to $80^{\circ}$ and sweep angles of 

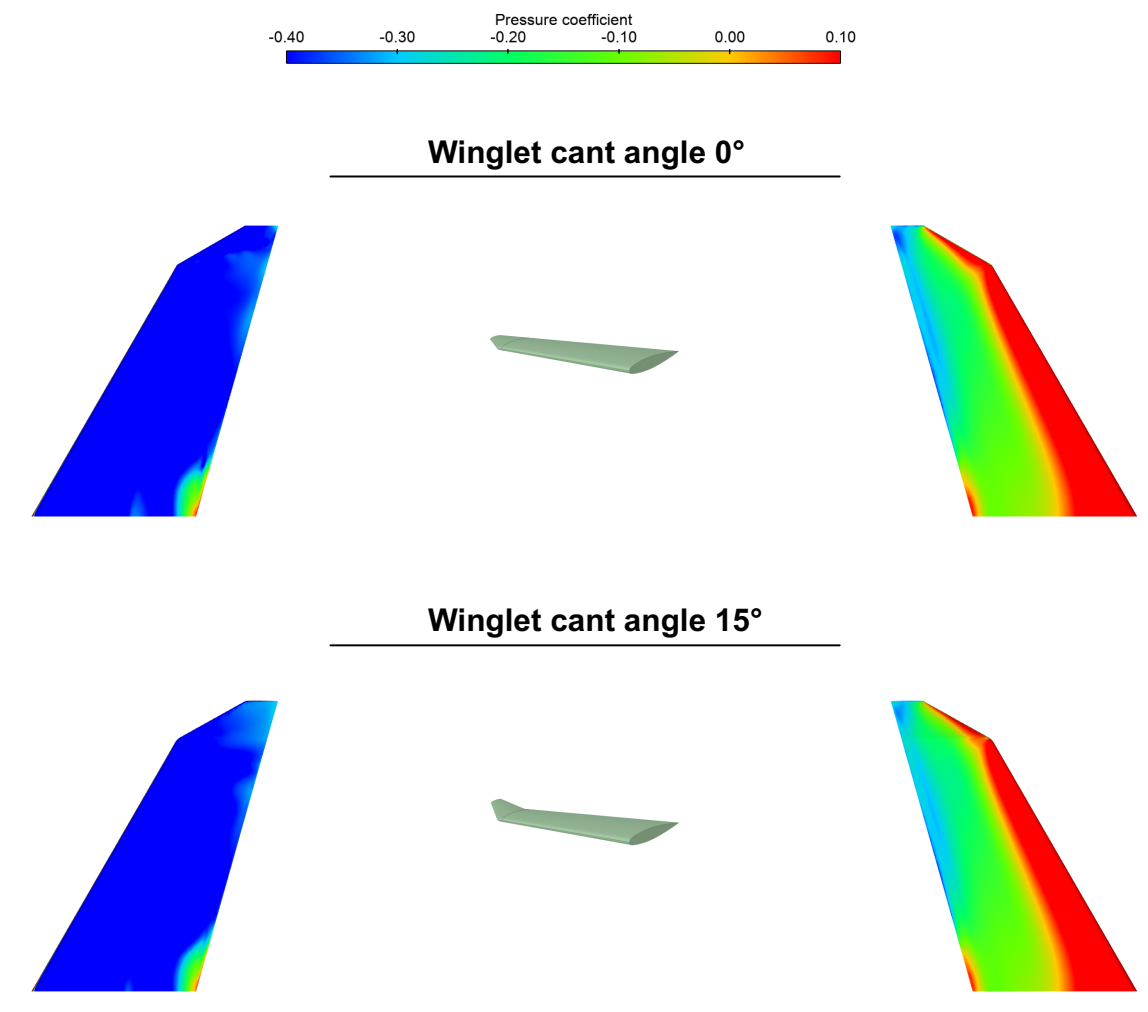

Winglet cant angle $45^{\circ}$
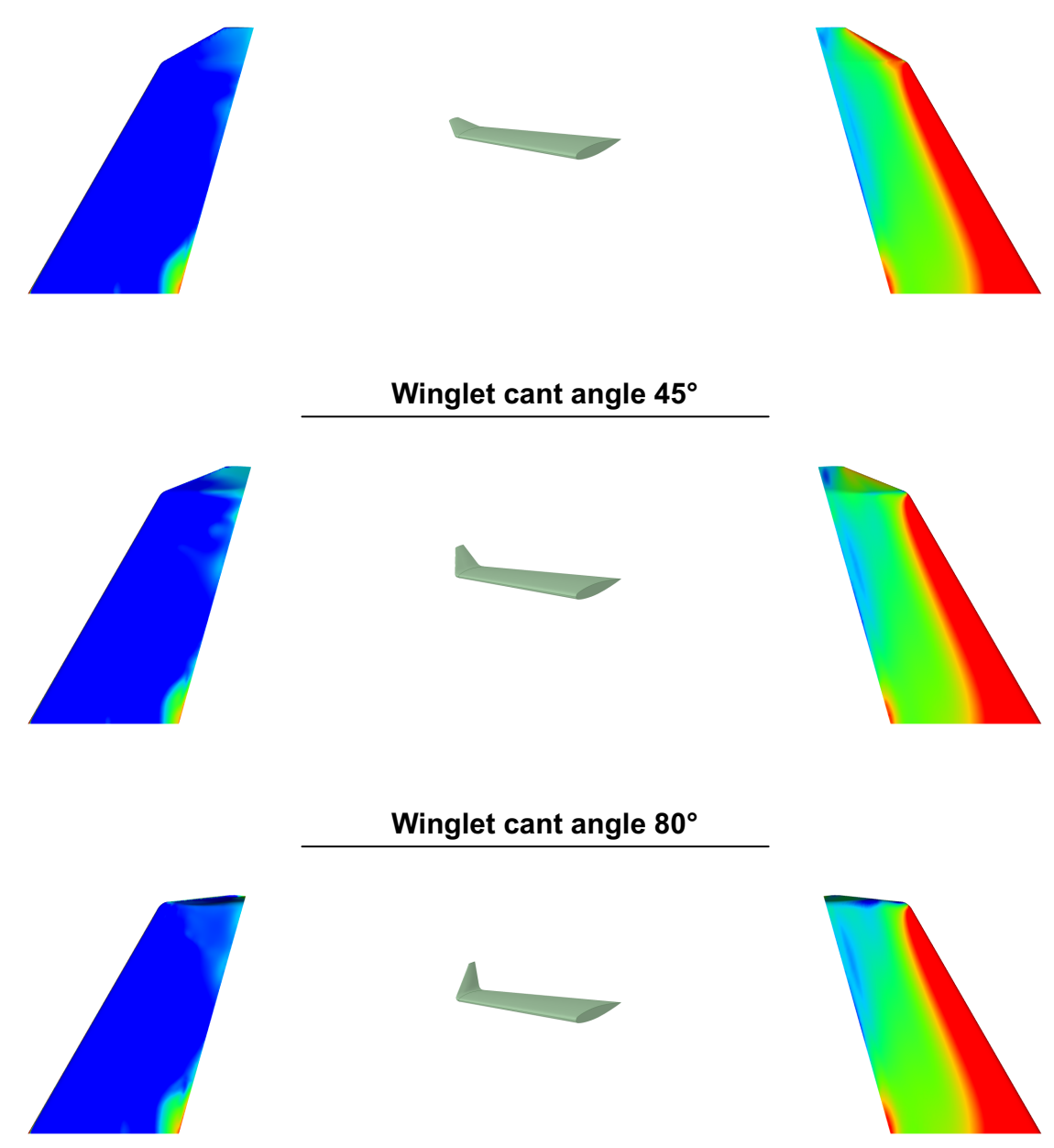

Winglet cant angle $80^{\circ}$

\section{Top surface}
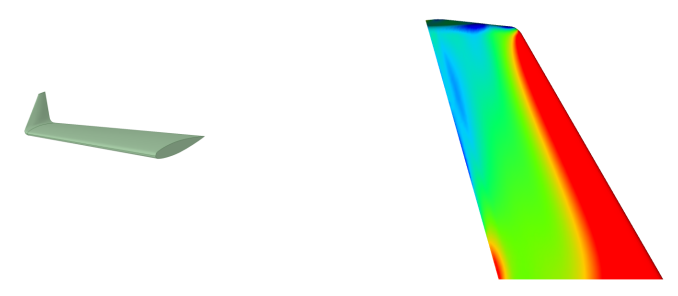

\section{Bottom surface}

Figure 18: Pressure coefficient on the wing surface at Mach number 0.8395 . Winglet sweep angle equal to $60^{\circ}$ and wing $A O A$ equal to $10^{\circ}$. 


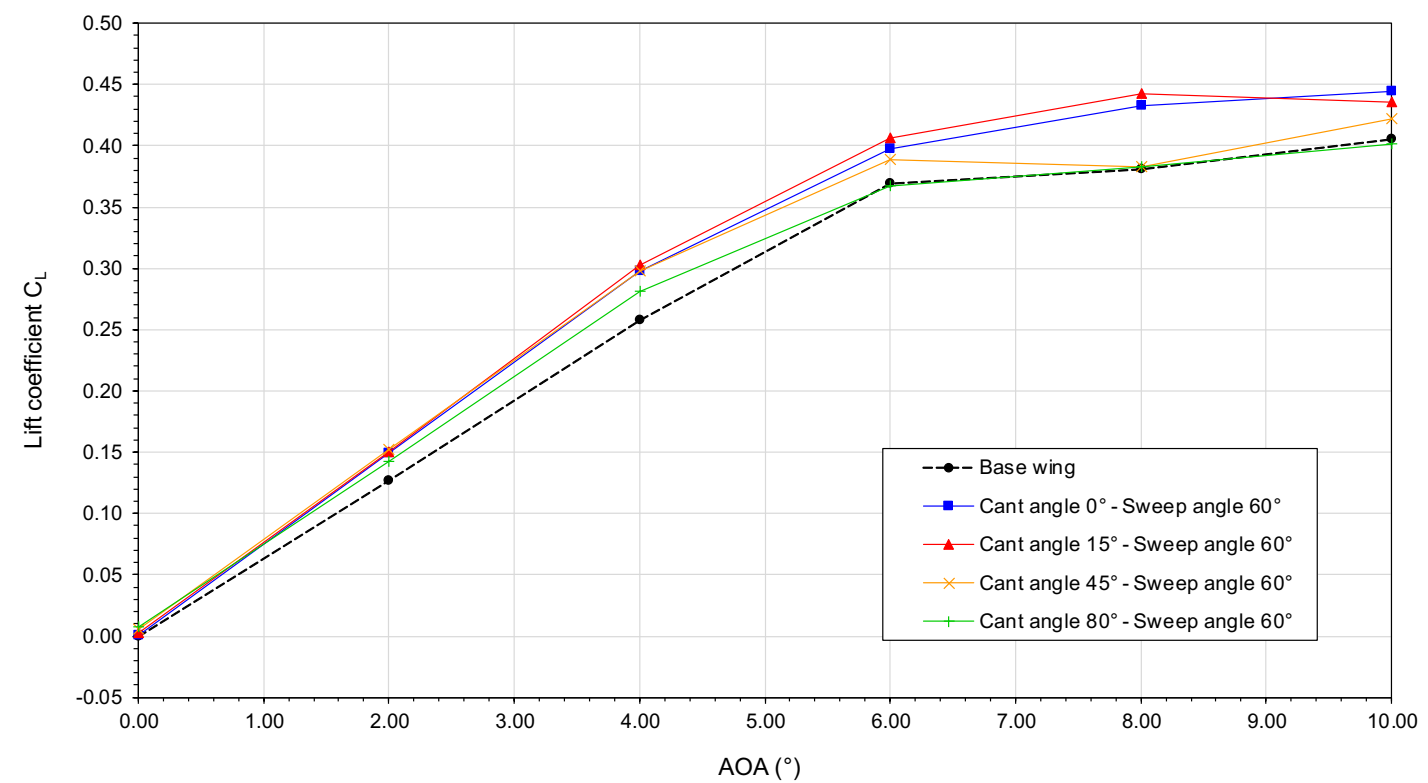

Figure 19: Lift coefficient versus angle-of-attack at Mach number 0.8395 , sweep angle $60^{\circ}$ and different values of cant angle.

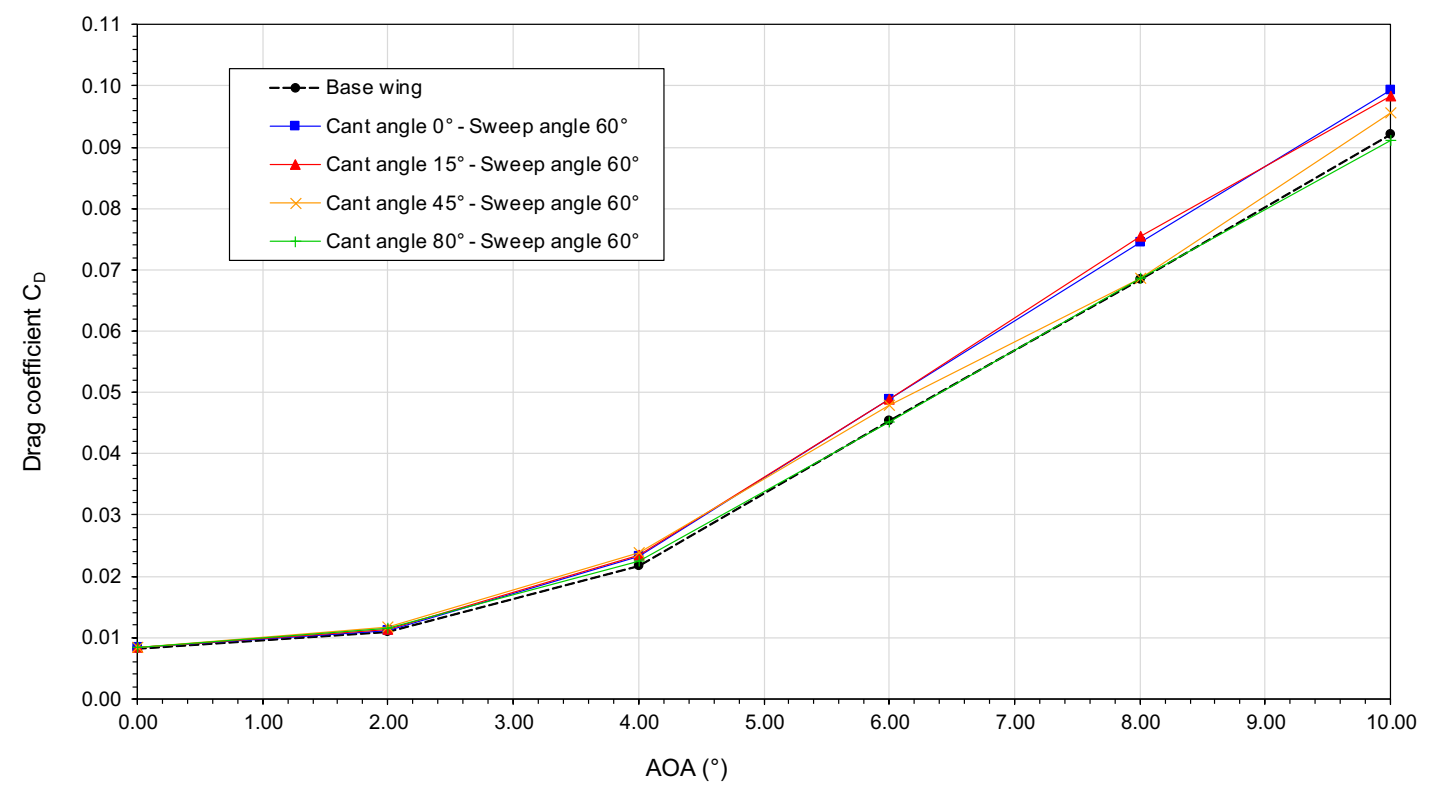

Figure 20: Drag coefficient versus angle-of-attack at Mach number 0.8395 , sweep angle $60^{\circ}$ and different values of cant angle. 
Table 6: $C_{D}$ and drag reduction percentage for a target $C_{L}$ equal to 0.1 at Mach number 0.8395 . The drag reduction percentage was computed with respect to the baseline wing, where positive values indicate drag reduction.

$\begin{array}{cccc}\text { Winglet cant angle } & \text { Winglet sweep angle } & C_{D} & \text { Drag reduction }(\%) \\ 0^{\circ} & 60^{\circ} & 0.010246 & \approx 0.8 \\ 15^{\circ} & 60^{\circ} & 0.010276 & \approx 0.5 \\ 45^{\circ} & 60^{\circ} & 0.010501 & \approx-1.5 \\ 80^{\circ} & 60^{\circ} & 0.010530 & \approx-1.9\end{array}$

Table 7: $C_{D}$ and drag reduction percentage for a target $C_{L}$ equal to 0.2 at Mach number 0.8395 . The drag reduction percentage was computed with respect to the baseline wing, where positive values indicate drag reduction.

$\begin{array}{cccc}\text { Winglet cant angle } & \text { Winglet sweep angle } & C_{D} & \text { Drag reduction }(\%) \\ 0^{\circ} & 60^{\circ} & 0.015319 & \approx 9.5 \\ 15^{\circ} & 60^{\circ} & 0.015319 & \approx 9.5 \\ 45^{\circ} & 60^{\circ} & 0.015829 & \approx 6.5 \\ 80^{\circ} & 60^{\circ} & 0.016085 & \approx 5.0\end{array}$

$45^{\circ}$ and $60^{\circ}$, the crossover point is located approximately between $2^{\circ}$ and $3^{\circ}$ of $A O A$, and for a sweep angle of $30^{\circ}$ the polars intersect at large $C_{L}$ values (worst case scenario).

From the previous discussion, we found that the sweep angle has a strong influence on the aerodynamic performance and, the best performance is obtained for a winglet sweep angle equal to $60^{\circ}$; therefore, for the remainder of this section we will focus our attention on the wing with a winglet sweep angle of $60^{\circ}$.

In figure 19 , the behavior of the lift coefficient is displayed as a function of the $A O A$. We can observe in this figure that up to an $A O A$ of $4^{\circ}$, the lift curves show a linear behavior. We can also note that the slope of the lift curve is almost the same for the cases with cant angles between $0^{\circ}$ and $45^{\circ}\left(\partial C_{L} / \partial A O A \approx 0.075\right.$ per degree $)$. For the case with cant angle equal to $80^{\circ}$ the slope is lower $\left(\partial C_{L} / \partial A O A \approx 0.068\right.$ per degree $)$, but still is higher than that of the baseline wing $\left(\partial C_{L} / \partial A O A \approx 0.064\right.$ per degree). In this figure, the maximum lift coefficient $C_{L_{\max }}$ is increased by as much as $10.5 \%$ for a cant angle of $0^{\circ}$, approximately $9.1 \%$ for a cant angle of $15^{\circ}$, about $4.2 \%$ for a cant angle of $15^{\circ}$, and for a cant angle of $80^{\circ}$ the value of $C_{L_{\max }}$ is reduced approximately $1 \%$. The reduction of $C_{L_{\max }}$ (as the cant angle is increased), is related to the reduction of the pressure differential towards the wingtip, as explained previously. Again, these results correlate well with the fact that winglets artificially increase the effective span of the wing; therefore, they have a direct impact on the lift behavior. Lastly, the use of the variable cant angle winglet does not appear to have any negative effect on the stall behavior, and all cases exhibit gentle stall characteristics.

It is important to mention that computing $C_{L_{\max }}$ and capturing the stall pattern in CFD is a difficult task, however, as we do not expect that the wing will operate at values close to $C_{L_{\max }}$ in cruise conditions, uncertainties in the computation of $C_{L_{\max }}$ can be tolerated.

It is also interesting to mention that even though the wing airfoil section is symmetric, the lift at zero $A O A$ or $C_{L_{0}}$ is not zero for large cant angles of the winglet device. For the winglet with a cant angle of $45^{\circ} C_{L_{0}} \approx 0.0055$, and for a winglet cant angle of $80^{\circ} C_{L_{0}} \approx 0.0065$. Although these values are low, they have the effect of introducing a small negative zero-lift angle or $\alpha_{z l}$, which is in the order of $-0.1^{\circ}$.

In figure 20, we plot the behavior of the drag coefficient as a function of the $A O A$. In this figure, we can observe that for $A O A$ values ranging from $0^{\circ}$ to $2^{\circ}$ all the winglet configurations generate almost the same drag. Then, as we pass by $A O A 4^{\circ}$ higher cant angles $\left(45^{\circ}\right.$ and $\left.80^{\circ}\right)$ translate in less drag for the same $A O A$ value. As the wing profile is symmetric, the minimum drag $C_{D_{\min }}$ is attained at $A O A 0^{\circ}$, and the use of the winglet does not appear to shift the horizontal location of $C_{D_{\min }}$.

Table 8: $C_{D}$ and drag reduction percentage for a target $C_{L}$ equal to 0.35 at Mach number 0.8395 . The drag reduction percentage was computed with respect to the baseline wing, where positive values indicate drag reduction.

$\begin{array}{cccc}\text { Winglet cant angle } & \text { Winglet sweep angle } & C_{D} & \text { Drag reduction }(\%) \\ 0^{\circ} & 60^{\circ} & 0.036936 & \approx 11.2 \\ 15^{\circ} & 60^{\circ} & 0.035148 & \approx 15.4 \\ 45^{\circ} & 60^{\circ} & 0.038042 & \approx 8.6 \\ 80^{\circ} & 60^{\circ} & 0.040936 & \approx 3.9\end{array}$



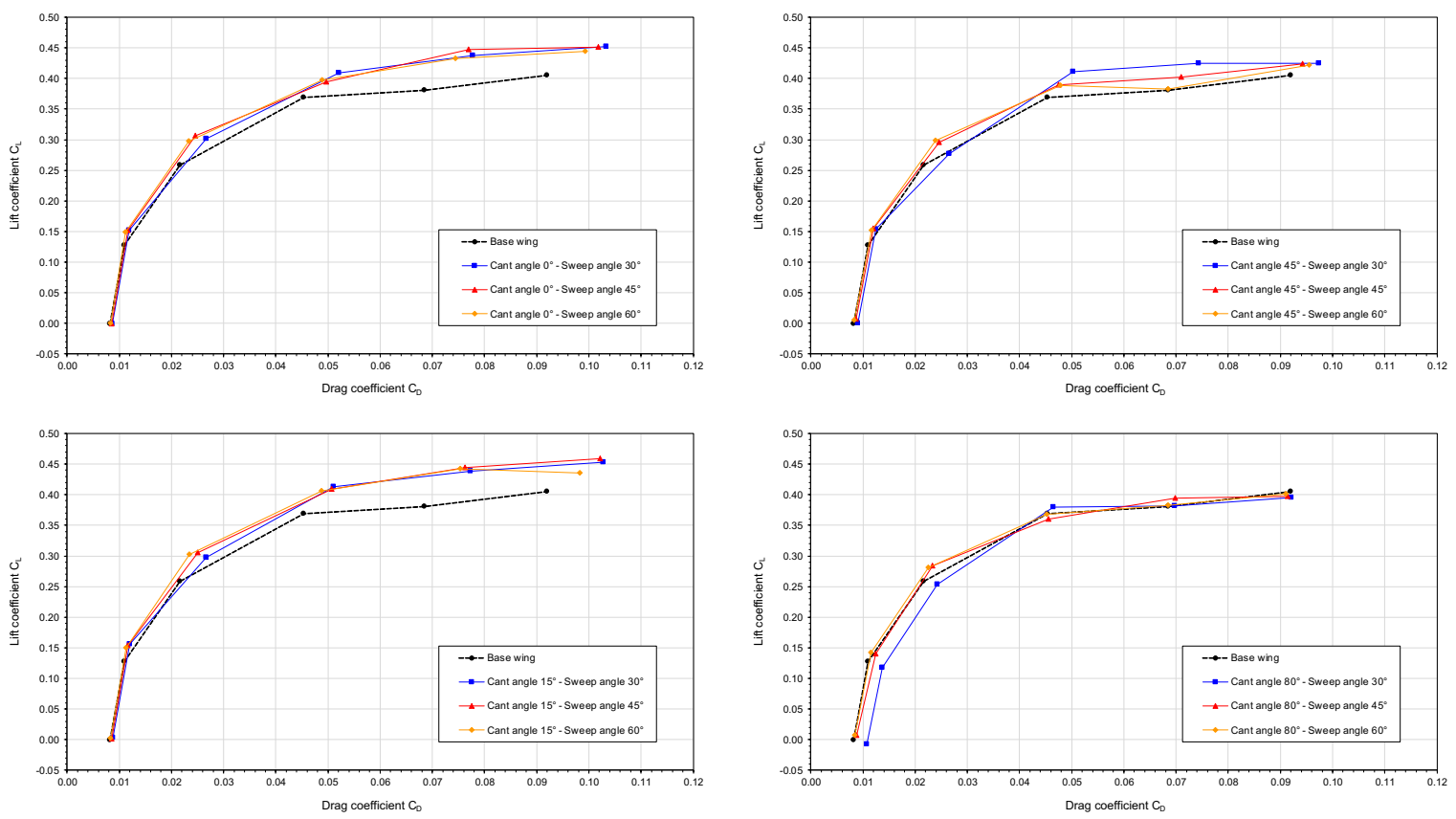

Figure 21: Drag polar at Mach number 0.8395. Each image corresponds to a fix cant angle and three different values of sweep angle.

The behavior of the lift-to-drag ratio $\left(C_{L} / C_{D}\right)$ as a function of the $A O A$ is plotted in figure 22 In this figure, it is found that $C_{L} / C_{D}$ increases very rapidly up to about $2^{\circ}$, at this point the maximum $C_{L} / C_{D}$ value is reached, then, $C_{L} / C_{D}$ gradually drops mainly because drag increases more rapidly than lift. For winglet cant angles of $0^{\circ}$ and $15^{\circ}$ the maximum $C_{L} / C_{D}$ is increased by approximately $12.0 \%$ in reference to the baseline wing, for a cant angle of $45^{\circ}$ the maximum $C_{L} / C_{D}$ is increased $\approx 8.8 \%$, and for a cant angle of $80^{\circ}$ the maximum $C_{L} / C_{D}$ is increased $\approx 4.8 \%$. The main point of interest about the $C_{L} / C_{D}$ curve is the fact that this ratio is maximum at an $A O A$ of about $2^{\circ}$ for all the configurations, that is, the use of the variable cant angle winglet does not change the $A O A$ at which the maximum $C_{L} / C_{D}$ occurs. It is at this $A O A$ that the wings will generate as much $C_{L}$ as possible with a small $C_{D}$ production.

From the results presented, it is clear that there is not a single winglet configuration that can give the best all-around drag reduction at every $A O A$. It was also clear that the winglet configuration with a sweep angle equal to $60^{\circ}$ gave the best results for different cant angle values. The results also show that $C_{L_{\max }}$ and the slope of the lift curves decreases as the winglet cant angle is increased, but the aerodynamic performance still is better or similar to that of the baseline wing. This suggests that the proposed variable cant angle winglet can also be used as a load alleviation mechanism. Thus, in the case of strong gusts or turbulence, the cant angle can be increased in order to reduce the lift force, hence decreasing the root bending moment.

\subsection{Aerodynamic performance at low Mach number $-M a=0.3$}

Hereupon, we discuss the results at Mach number equal to 0.3, which might well correspond to the velocities encountered at take-off, climb, descent and approach flight conditions on subsonic civil transport aircraft. We explore $A O A$ values up to $20^{\circ}$, which correspond to the large values of $A O A$ that could be encountered during take-off. It is also important to point out that the trends we will present in this section are very similar to those presented in section 5.1. but as the Mach number is relative low, there are neither wave drag contributions nor compressibility effects.

In figures 23 25, we plot the drag polars at a fixed sweep angle and different cant angles. As opposed to the cases at Mach number 0.8395, where it was clear that the sweep angle shifted upwards the drag polar, at this low Mach number we do not experience such large variations in the drag polars. For $A O A$ values lower than $6^{\circ}$ and for all cant angle configurations, the drag difference between the baseline wing and the wing with winglets is almost negligible or negative (meaning that it generates less drag). At $A O A$ larger than $6^{\circ}$, the effect on the improvement of the drag polars is clearer except for the case of cant angle equal to $80^{\circ}$, where we can note a considerable reduction in $C_{L}$. 


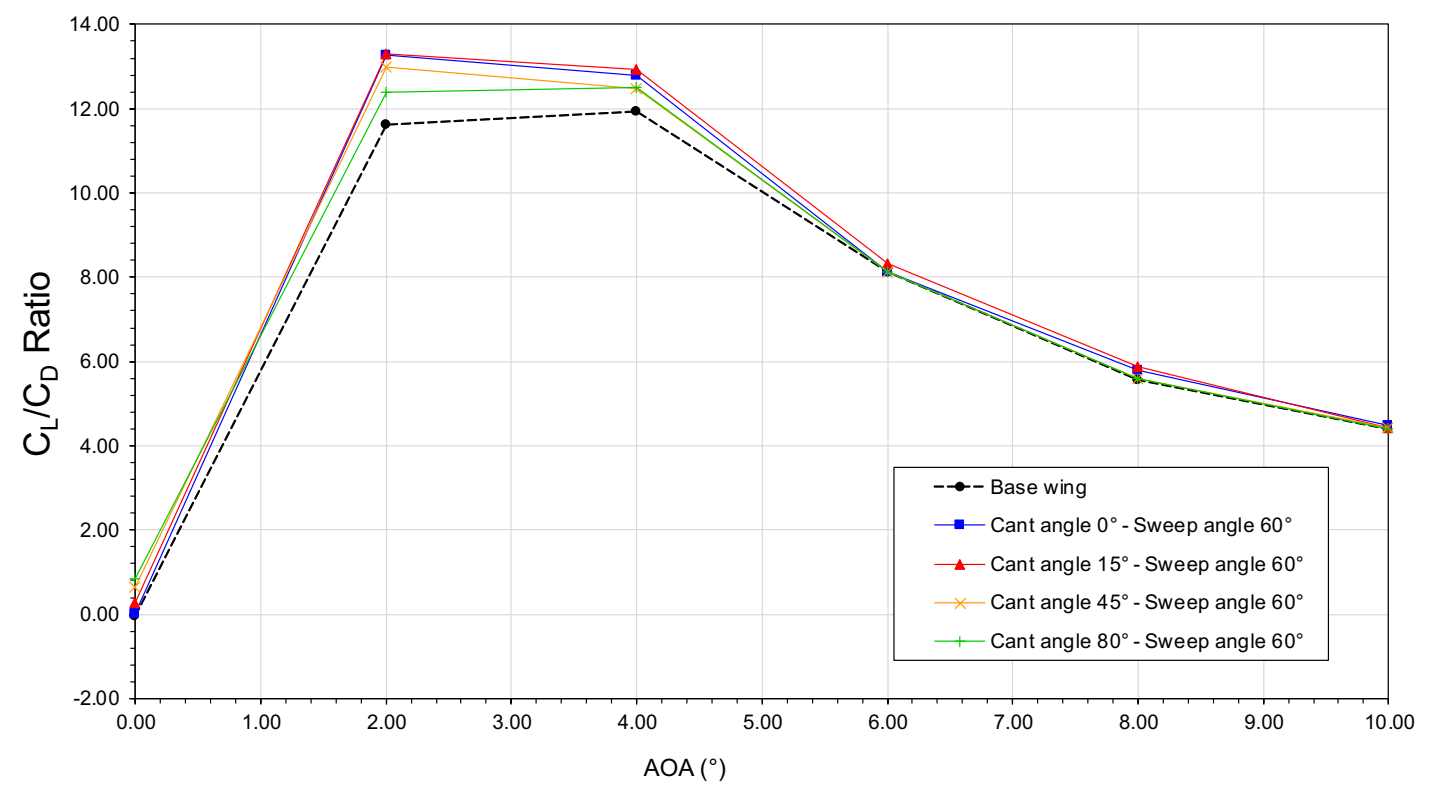

Figure 22: Lift-to-drag ratio versus angle-of-attack at Mach number 0.8395 , sweep angle $60^{\circ}$ and different values of cant angle.

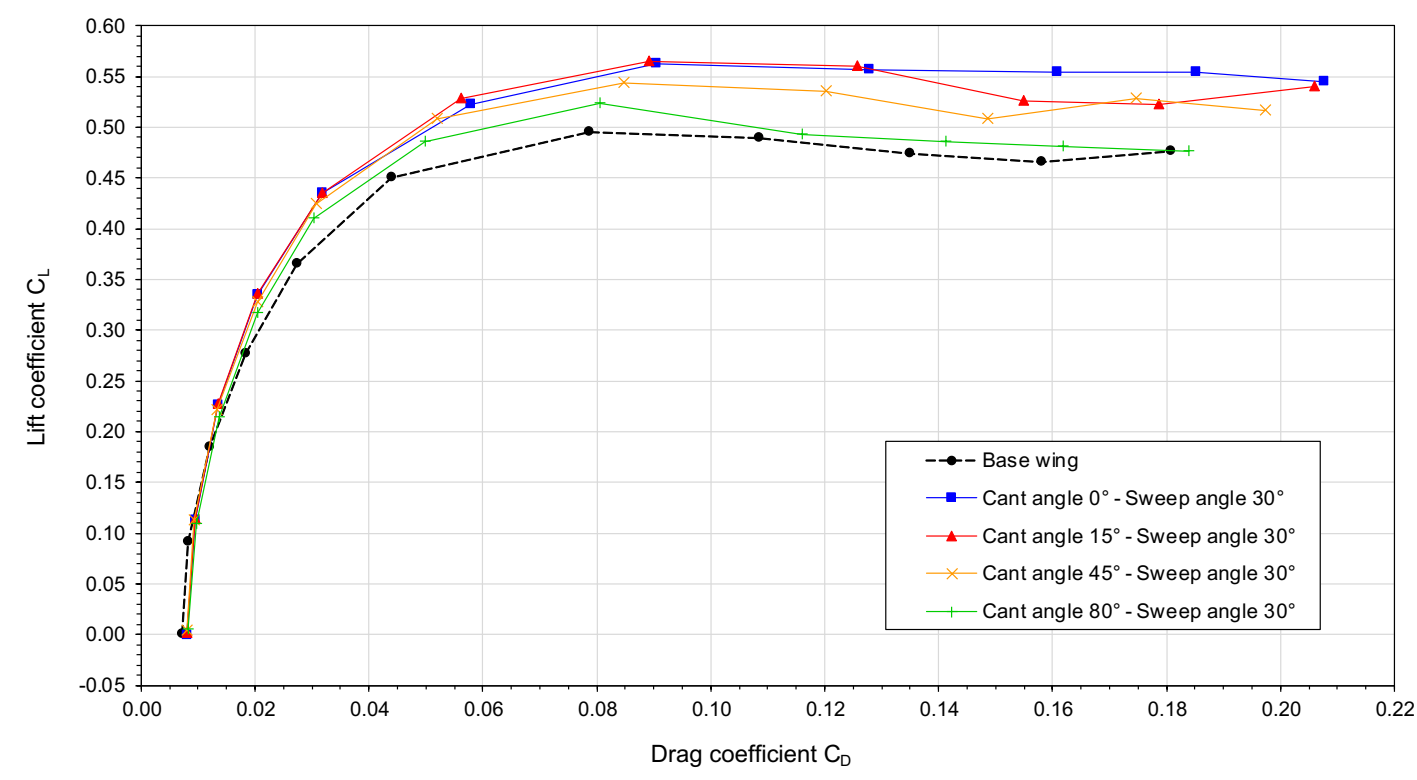

Figure 23: Drag polar at Mach number 0.3, sweep angle $30^{\circ}$ and different values of cant angle. 


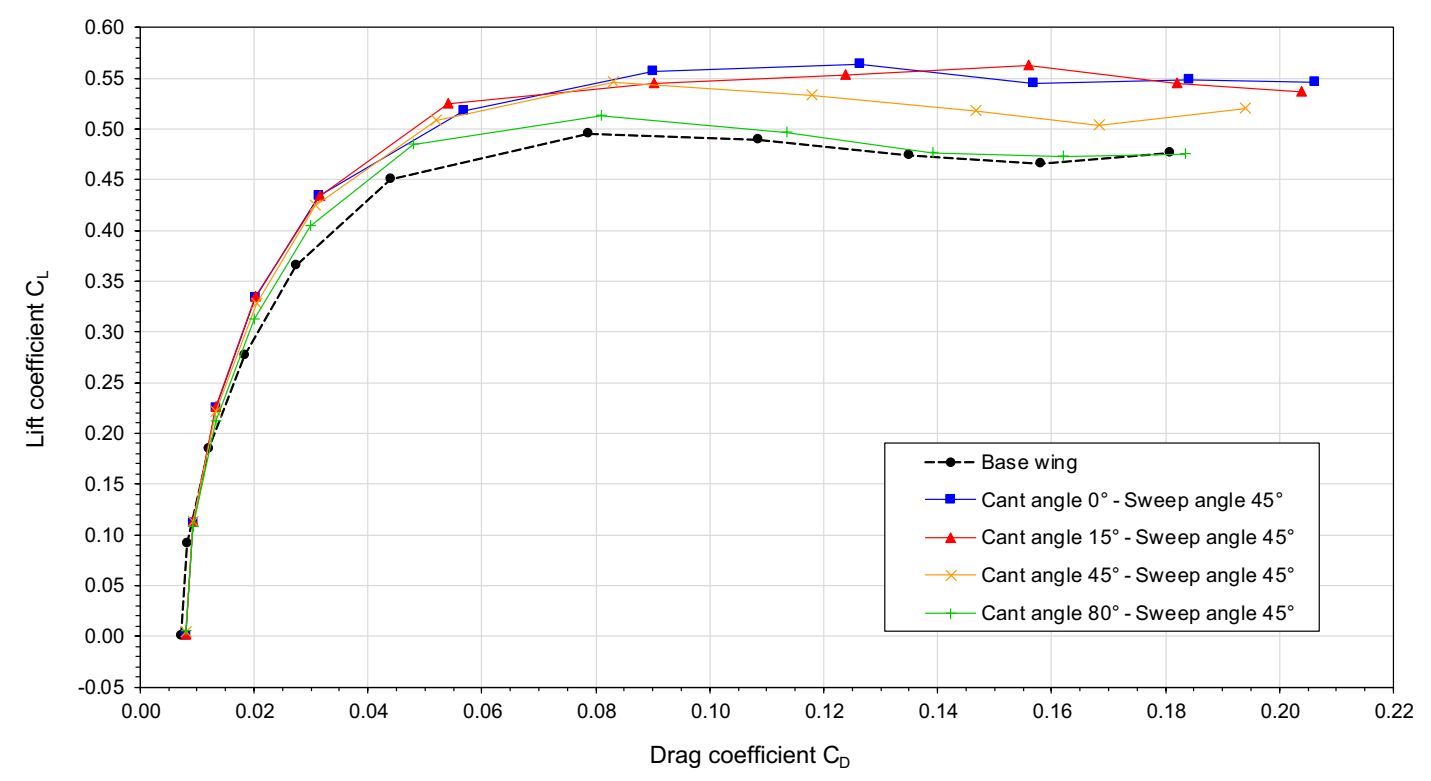

Figure 24: Drag polar at Mach number 0.3, sweep angle $45^{\circ}$ and different values of cant angle

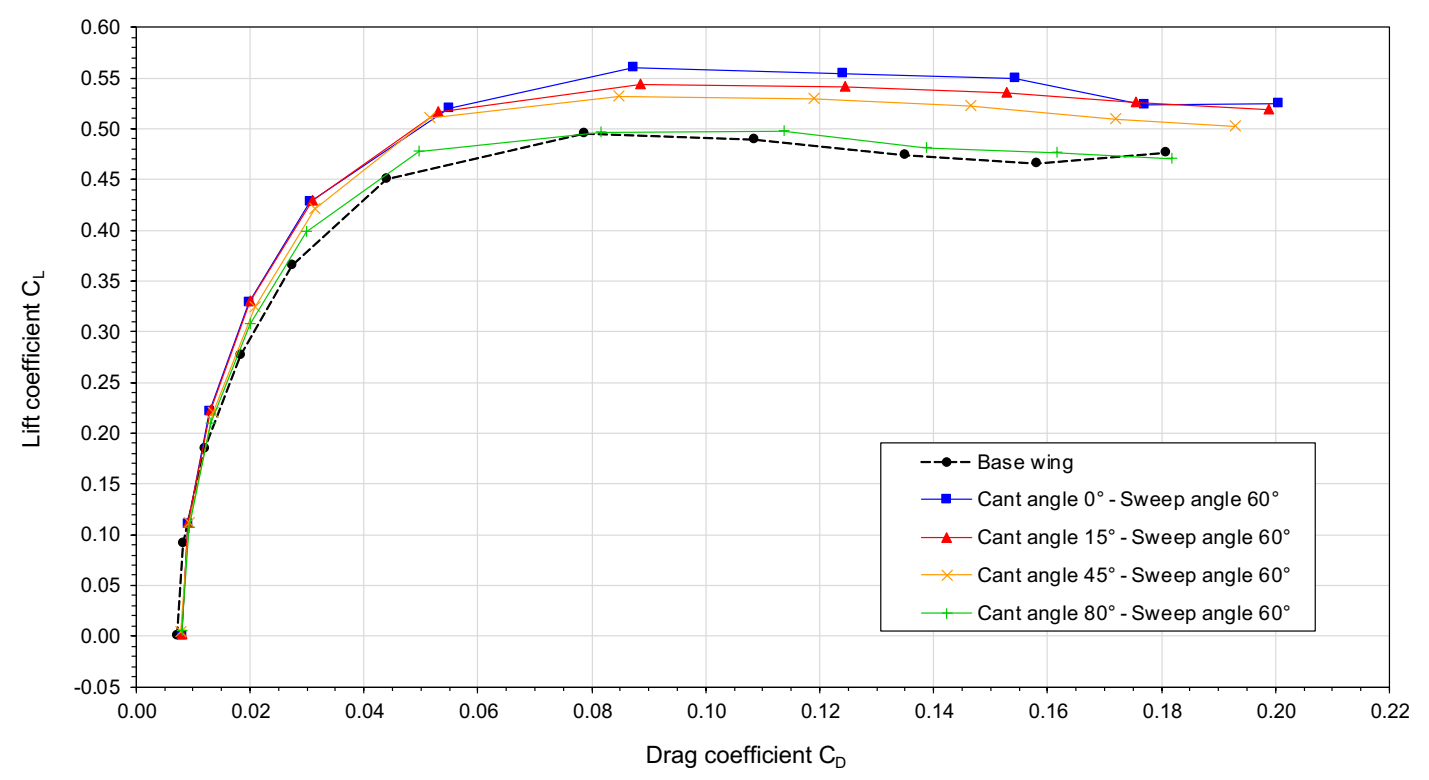

Figure 25: Drag polar at Mach number 0.3, sweep angle $60^{\circ}$ and different values of cant angle 
Table 9: $C_{D}$ and drag reduction percentage for a target $C_{L}$ equal to 0.25 at Mach number 0.3. The drag reduction percentage was computed with respect to the baseline wing, where positive values indicate drag reduction.

$\begin{array}{cccc}\text { Winglet cant angle } & \text { Winglet sweep angle } & C_{D} & \text { Drag reduction (\%) } \\ 0^{\circ} & 60^{\circ} & 0.014742 & \approx 10.0 \\ 15^{\circ} & 60^{\circ} & 0.014820 & \approx 9.5 \\ 45^{\circ} & 60^{\circ} & 0.015622 & \approx 4.6 \\ 80^{\circ} & 60^{\circ} & 0.015961 & \approx 2.5\end{array}$

Table 10: $C_{D}$ and drag reduction percentage for a target $C_{L}$ equal to 0.4 at Mach number 0.3 . The drag reduction percentage was computed with respect to the baseline wing, where positive values indicate drag reduction.

$\begin{array}{cccc}\text { Winglet cant angle } & \text { Winglet sweep angle } & C_{D} & \text { Drag reduction }(\%) \\ 0^{\circ} & 60^{\circ} & 0.027495 & \approx 19.0 \\ 15^{\circ} & 60^{\circ} & 0.027784 & \approx 18.4 \\ 45^{\circ} & 60^{\circ} & 0.029152 & \approx 14.5 \\ 80^{\circ} & 60^{\circ} & 0.030366 & \approx 10.1\end{array}$

The reduction of $C_{L}$ seen in figures $23 \mid 25$ as the cant angle is increased, and that of $C_{L_{\max }}$ and the slope of the lift curve (figure 26p, are due to the pressure differential reduction towards the wingtips, as already explained in section 5.1. In figure 27, we plot the pressure coefficient on the wing surface for three configurations. In this figure, we can observe that for large winglet cant angles the pressure differential is reduced towards the wingtips, and this behavior is responsible for the decrement of the maximum $C_{L}$ and the reduction of the slope of the lift curve seen in figure 26. As for the $C_{D_{\min }}$ concerns, for all cases shown in figures 23 25. $C_{D_{\min }}$ is increased with respect to the baseline wing by approximately $4.0 \%$.

In tables 9 11, we present the $C_{D}$ for three $C_{L}$ targets in the linear regime of the lift curves. The values studied correspond to $C_{L}$ equal to 0.25 (approximately the $C_{L}$ value corresponding to an $A O A$ of $4^{\circ}$ where the maximum $C_{L} / C_{D}$ happens), and two high lift cases ( $C_{L}$ equal to 0.4 and 0.45 ). From the results summarized in these tables, we can deduce that as the can angle is increased the gains in drag reduction are shortened, and the largest reductions of drag are obtained for cant angles between $0^{\circ}$ and $15^{\circ}$. In the results presented in table 11 , the gains in drag reduction are lessened because we are close to $C_{L_{\max }}$, and almost in the non-linear regime of the lift curves, hence, the slopes of the lift curves are lower.

In figure 26, we plot the lift coefficient as a function of the $A O A$ for a sweep angle equal to $60^{\circ}$. The curves depicted in this figure show a linear behavior up to approximately $10^{\circ}$, then, $C_{L_{\max }}$ is reached, and the wings stall. It is noteworthy that the stall behavior of all the cases is similar. In this figure, $C_{L_{\max }}$ is increased in reference to the baseline wing for all winglet cant angle configurations. For a cant angle of $0^{\circ}$ the maximum $C_{L}$ is increased by as much as $13.0 \%$, approximately $10.0 \%$ for a winglet cant angle of $15^{\circ}$, for a cant angle of $45^{\circ}$ by approximately $7.0 \%$, and for a cant angle of $80^{\circ}, C_{L_{\max }}$ is increased by approximately $1.0 \%$. The slope of the lift curves is almost the same for the cases with cant angles between $0^{\circ}$ and $45^{\circ}\left(\partial C_{L} / \partial A O A \approx 0.053\right.$ per degree). For the case with a cant angle equal to $80^{\circ}$ the slope is $\partial C_{L} / \partial A O A \approx 0.049$ per degree. Lastly, the slope of the baseline wing is $\partial C_{L} / \partial A O A \approx 0.045$ per degree.

In figure 28, we plot the behavior of the drag coefficient as a function of the $A O A$. In this figure, we can observe that for $A O A$ values ranging from $0^{\circ}$ to $6^{\circ}$ all the winglet configurations generate almost the same drag. Then, as we pass by $A O A 8^{\circ}$ higher cant angles $\left(45^{\circ}\right.$ and $\left.80^{\circ}\right)$ translate in less drag for the same $A O A$ value. From the results presented, the largest drag reduction at high $A O A$ is obtained with winglets at cant angle equal to $80^{\circ}$; however, this winglet configuration greatly reduces the maximum $C_{L}$ which is not desirable since at low Mach number large $A O A$ are needed to reach the required lift, especially during take-off.

Table 11: $C_{D}$ and drag reduction percentage for a target $C_{L}$ equal to 0.45 at Mach number 0.3 . The drag reduction percentage was computed with respect to the baseline wing, where positive values indicate drag reduction.

$\begin{array}{cccc}\text { Winglet cant angle } & \text { Winglet sweep angle } & C_{D} & \text { Drag reduction (\%) } \\ 0^{\circ} & 60^{\circ} & 0.036458 & \approx 16.7 \\ 15^{\circ} & 60^{\circ} & 0.036273 & \approx 17.1 \\ 45^{\circ} & 60^{\circ} & 0.038001 & \approx 13.1 \\ 80^{\circ} & 60^{\circ} & 0.042939 & \approx 1.9\end{array}$




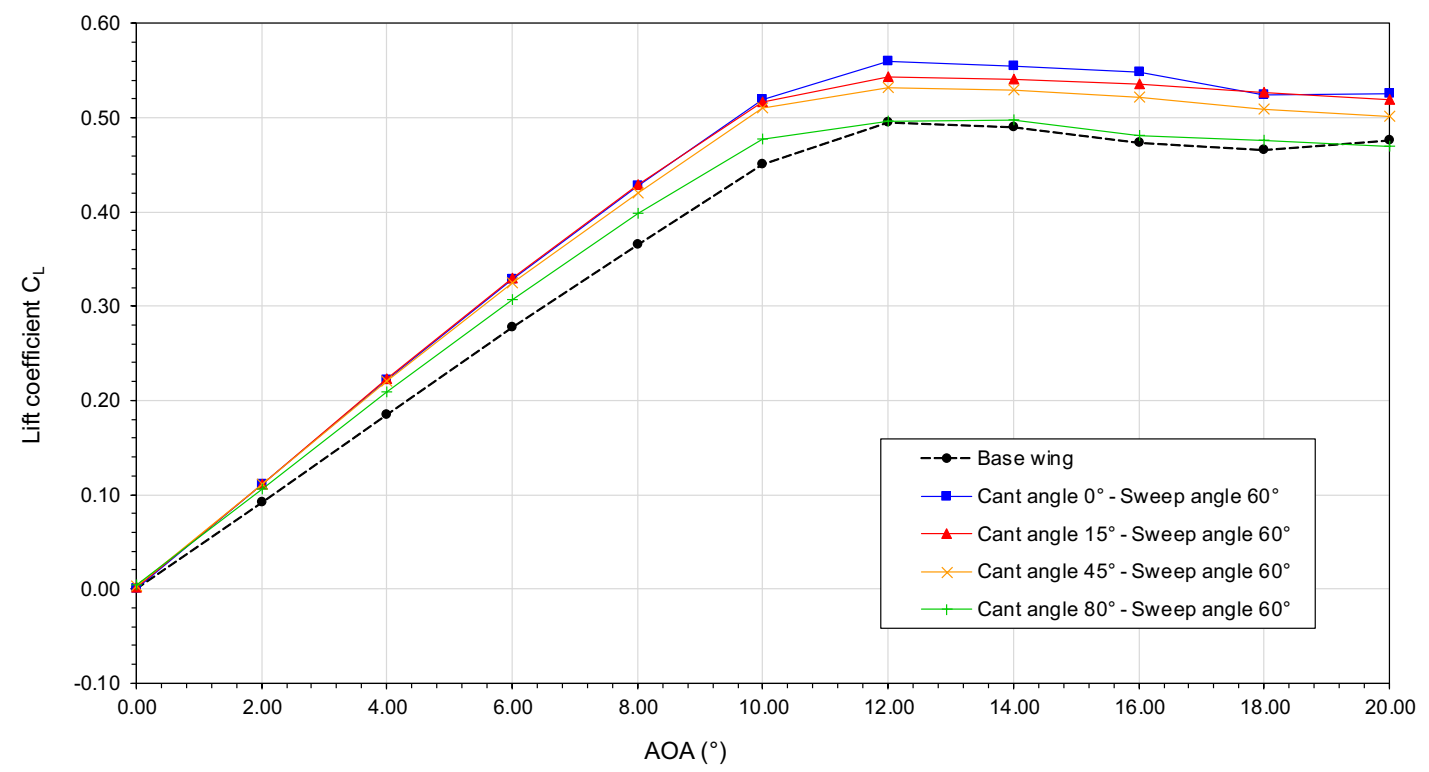

Figure 26: Lift coefficient versus angle-of-attack at Mach number 0.3, sweep angle $60^{\circ}$ and different values of cant angle.

The behavior of $C_{L} / C_{D}$ as a function of the $A O A$ is plotted in figure 29, where it can be seen that the maximum value of $C_{L} / C_{D}$ occurs at $4^{\circ}$ for all cases. For winglet cant angles of $0^{\circ}$ and $15^{\circ}$ the maximum $C_{L} / C_{D}$ is increased by approximately $10.5 \%$ in reference to the baseline wing, for a cant angle of $45^{\circ}$ the maximum $C_{L} / C_{D}$ is increased $\approx 5.0 \%$, and for a cant angle of $80^{\circ}$ the maximum $C_{L} / C_{D}$ is increased $\approx 3.0 \%$.

Finally, as for the case at $M a=0.8395$, the winglet configuration with a sweep angle equal to $60^{\circ}$ gave the best results for different cant angle values.

\subsection{Comparison of the aerodynamic performance at low and high Mach numbers}

To better understand the impact of high Mach number and compressibility effects on the aerodynamic performance, in figures 30 and 31 we plot the results at $M a=0.3$ and $M a=0.8395$, together. In figure 30, we plot the drag polars for the two design Mach numbers, as it can be seen, compressibility plays an important role on the aerodynamic performance. At high Mach numbers, compressibility affects $C_{L}$ and $C_{D}$ detrimentally. First, it reduces $C_{L_{\max }}$, and secondly, it increases the drag for a given $C_{L}$, especially for high $A O A$. This behavior stems from the alteration of the pressure distribution due to shock waves forming on the wing surface. It is interesting to highlight that at high Mach number and low $A O A$, the wing with winglets seem to work better than at low Mach number and low $A O A$, as $C_{D_{\min }}$ is slightly reduced in reference to the baseline wing.

The behavior of $C_{L}$ as a function of $A O A$ is plotted in figure 31, where we can identify two important aspects of the lift curves at high Mach number. First, the reduction of $C_{L_{\max }}$, and second, the increment of the lift curves slope, which in practice means that a smaller $A O A$ is required to generate a given $C_{L}$. However, more drag is produced due to compressibility effects (shock waves). It is also important to highlight that the stall characteristics for both Mach numbers are similar.

\subsection{Winglet settings during flight operations}

From the previous discussion, it is clear that there is not a single winglet configuration that can give the best all-around drag reduction at every flight phase. It was also clear that the winglet configuration with a sweep angle equal to $60^{\circ}$ gave the best results for different cant angle values. Hereafter, and based on the results presented in sections 5.1 5.3 we propose how the winglet cant angle could be set to obtain the best aerodynamic performance at a given flight phase. The suggested winglet settings for each flight phase are illustrated in figure 32 . The recommended winglet configurations 

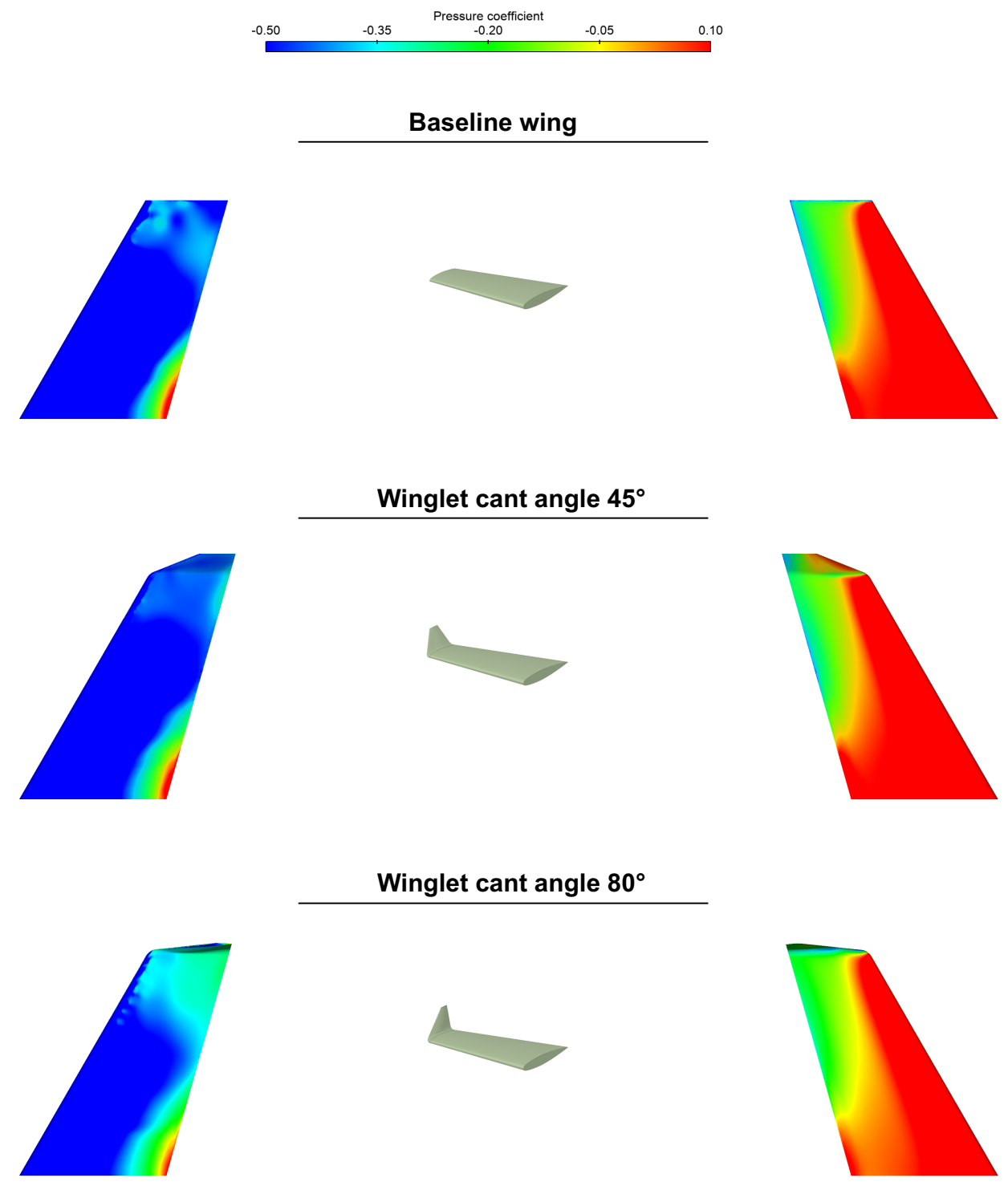

\section{Top surface}

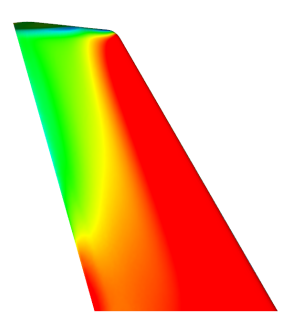

Bottom surface

Figure 27: Pressure coefficient on the wing surface at Mach number 0.3. Winglet sweep angle equal to $60^{\circ}$ and wing $A O A$ equal to $14^{\circ}$. 


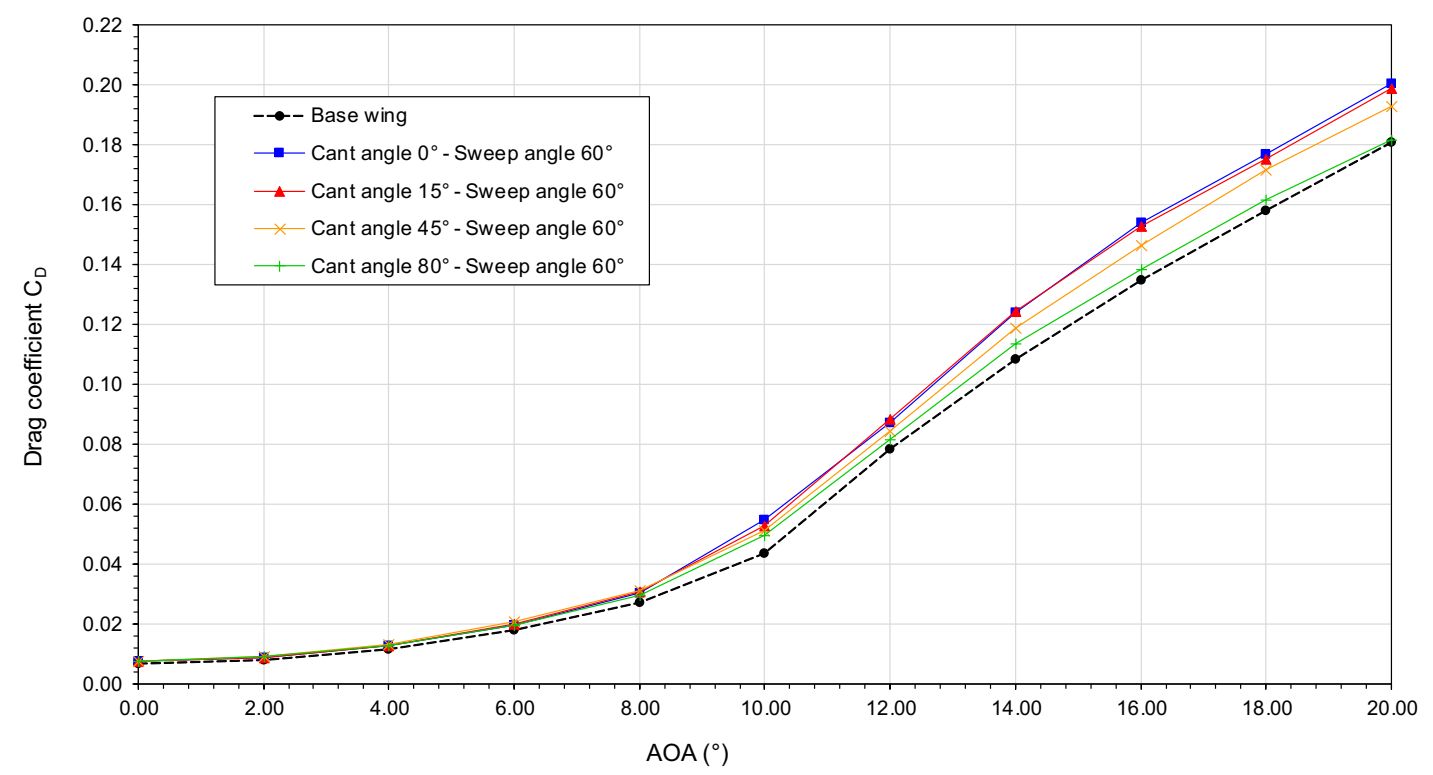

Figure 28: Drag coefficient versus angle-of-attack at Mach number 0.3, sweep angle $60^{\circ}$ and different values of cant angle.

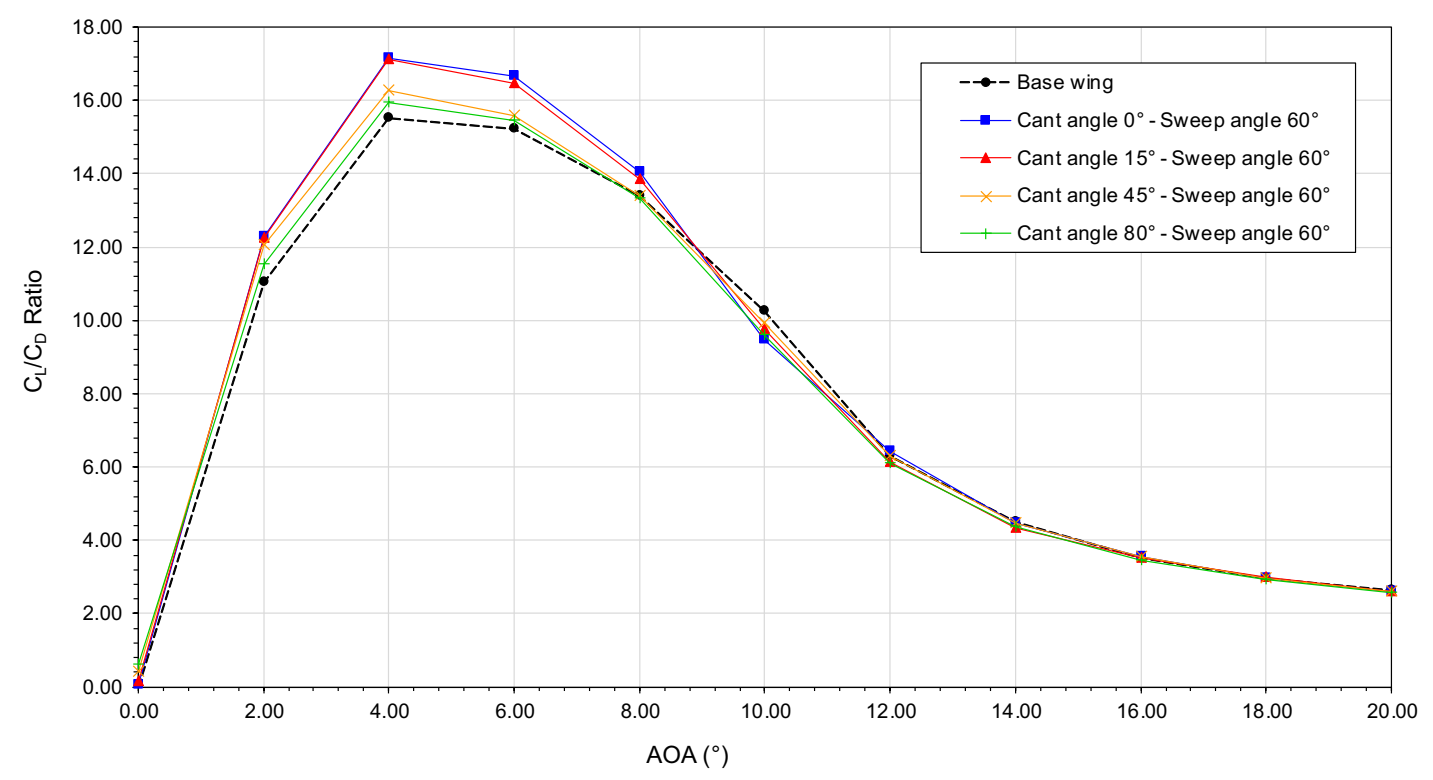

Figure 29: Lift-to-drag ratio versus angle-of-attack at Mach number 0.3, sweep angle $60^{\circ}$ and different values of cant angle. 


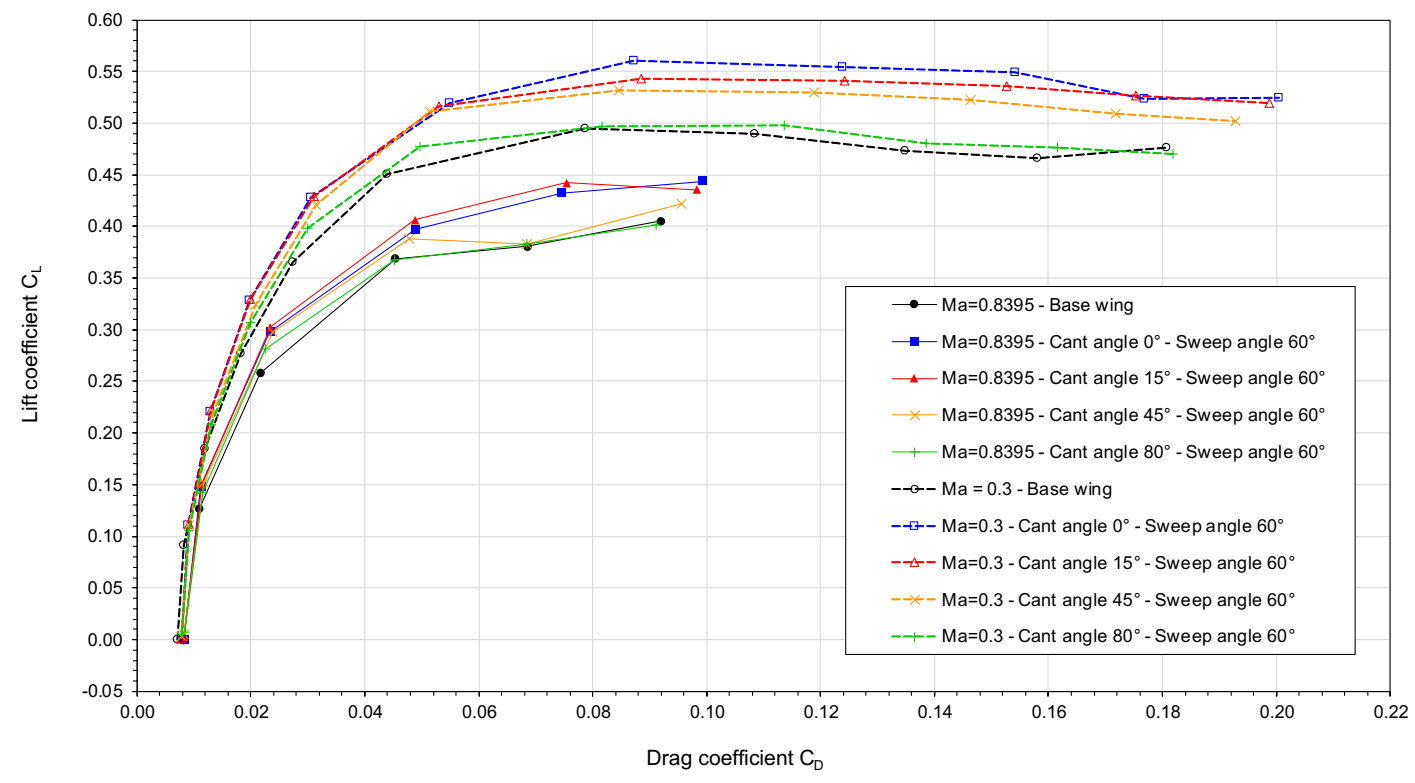

Figure 30: Drag polar for a winglet sweep angle of $60^{\circ}$ and different cant angles. The results at $M a=0.8395$ are plotted using continuous lines and those at $M a=0.3$ are plotted with dashed lines.

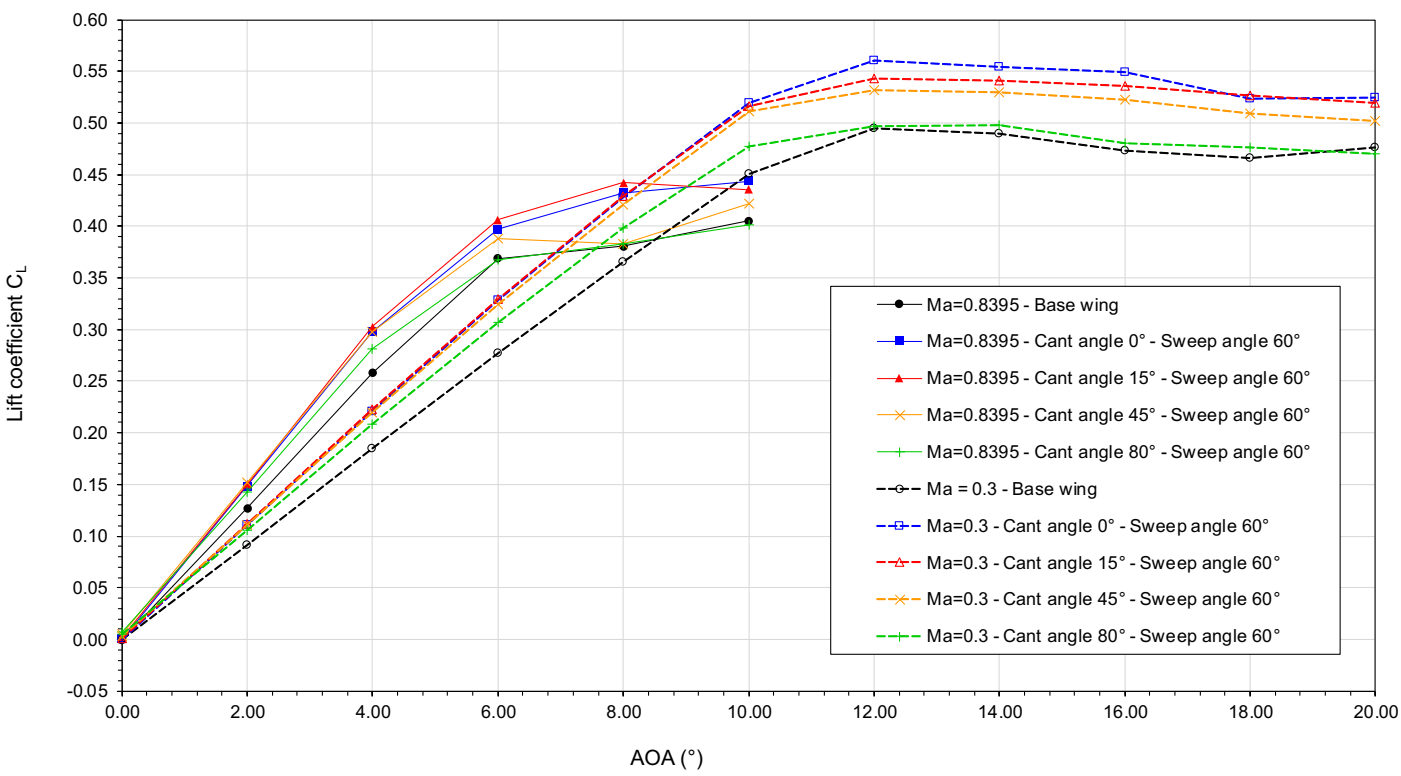

Figure 31: Lift coefficient versus angle-of-attack for a winglet sweep angle of $60^{\circ}$ and different cant angles. The results at $M a=0.8395$ are plotted using continuous lines and those at $M a=0.3$ are plotted with dashed lines. 


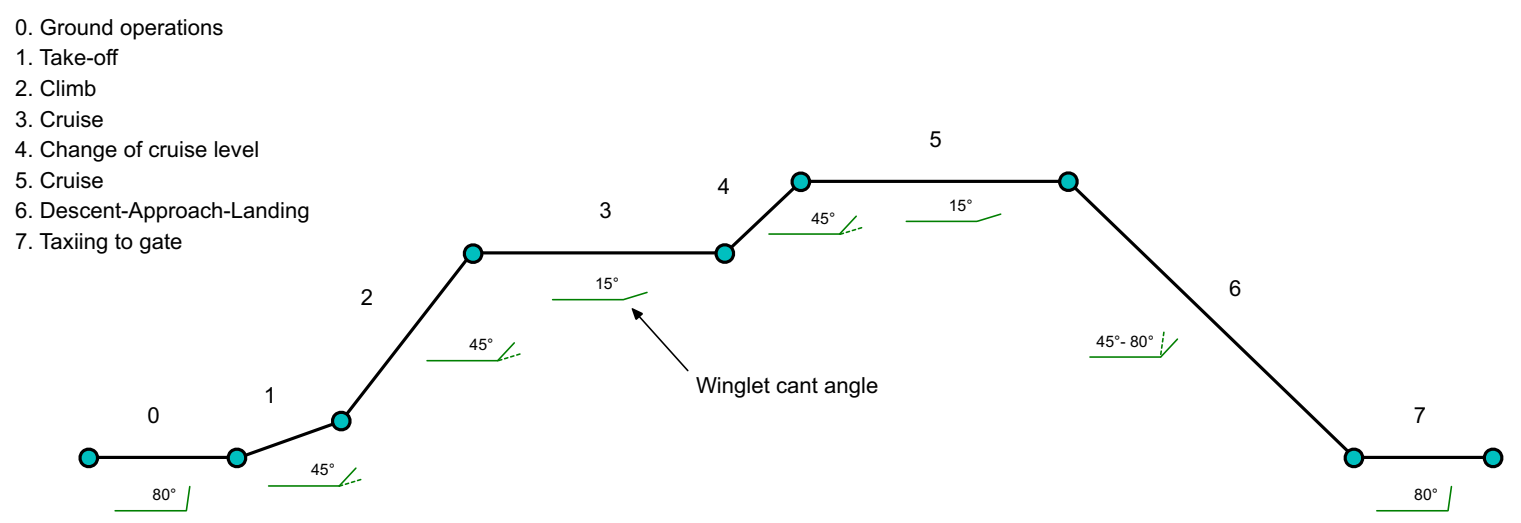

Figure 32: Winglet configuration during different flight phases.

were chosen in base of the improvements in the aerodynamic performance with respect to the baseline wing. Hereafter, we summarized the best settings according to the given flight phase:

- During ground operations, it is suggested to use a cant angle of $80^{\circ}$ in order to reduce the wingspan and meet gate clearance requirements.

- At take-off and initial climb (where compressibility effects are not strong), it is recommended to use a winglet cant angle of $45^{\circ}$. This configuration has a higher lift-slope and generates less drag for a target lift. However, a winglet cant angle of $15^{\circ}$ can also be used, this selection criterion can be based on weather conditions, take-off weight, or other operational requirements (such as climb rate).

- At cruise (high Mach number), it is recommended to use a cant angle of $15^{\circ}$. This setting will give the largest drag reduction for a given lift, with the exception for the case of cant angle equal to $0^{\circ}$. This selection is justified mainly because it generates less wing bending moments.

- At cruise level change, it is recommended to use a cant angle of $45^{\circ}$, but a value of $15^{\circ}$ is also acceptable. These configurations have large lift-slope and generate less drag for a target lift.

- During descent, it is recommended to use a cant angle of $45^{\circ}$. In our analysis, we did not favor configurations with a cant angle value equal to $80^{\circ}$ because they reduce the maximum lift coefficient and the slope of the lift curve.

- After landing and when taxiing to the gate, it is suggested to use a cant angle of $80^{\circ}$ in order to the reduce wingspan and meet gate clearance requirements.

The device studied can also be used as a load alleviation mechanism. So in case of strong gusts or turbulence, the cant angle can be increased to $80^{\circ}$ reducing in this way the maximum lift and the slope of the lift curve, therefore reducing the wing bending moments, and this might be particularly helpful during descent and landing with adverse weather conditions.

It is worth mentioning that the proposed winglet configurations show similar characteristics to those of fixed winglets already in use in civil transport aircraft. For example, the cant angle configuration of $15^{\circ}$ is very similar to the raked winglet, and the cant angle configuration of $45^{\circ}$ is close to the blended and canted winglets (refer to figure 1 ).

\section{Conclusions and perspectives}

In this manuscript, we have studied the use of variable cant angle winglets which could potentially allow aircraft to get the best all-around performance in terms of drag reduction over different flight phases. While the wing studied does not correspond to an actual wing used in civil transport aircraft, the insight gathered can be used to set the guidelines for the design of variable cant angle winglets and the adjustment of their cant angle during flight.

During this work, we considered high and low Mach number values (0.8395 and 0.3, respectively) and different angle-of-attack values. Thus, we aimed at covering take-off, climb, descent, and cruise conditions. All the quantitative results suggest that by carefully controlling the winglet cant angle, noticeable drag reductions for the same lift value can be obtained at high and low Mach numbers. It was also observed that the variable cant angle winglets do not have 
adverse effects on the stall behavior and the $A O A$ at which $C_{L_{\max }}$ and $C_{D_{\min }}$ occurs. It also worth noting that at high cant angle values $\left(80^{\circ}\right)$, the maximum lift coefficient and the slope of the lift curve is reduced (but their values are still larger than the values of the baseline wing); therefore, the proposed winglet could potentially be used as a load alleviation system.

Furthermore, it was also found that large winglet sweep angle values have a positive impact on the aerodynamic performance improvements gained by using the proposed winglet. The improvement due to sweep angle is mainly due to a combination of reduced parasite drag, decreased wave drag at high Mach number, and the effect of the inboard lift force generated by the winglet.

In summary, the following benefits have been found:

- Increased lift curve slope.

- Increased maximum lift.

- Increased lift-to-drag ratio.

- No negative effects on stall behavior due to lift production enhancement.

- For the same Mach number, the $A O A$ for $C_{L_{\max }}$ and maximum $C_{L} / C_{D}$ remains almost invariable.

- Crossover point at $A O A$ values below $2^{\circ}-3^{\circ}$, and as low as $0^{\circ}$. As a consequence, total drag reduction for the same lift above the crossover point.

- The increase of the winglet cant angle does not add the extra wing root bending moment that would be encountered if the wingspan were simply increased by the span of the winglet.

On the other side, the following shortcomings have been found:

- Increased parasite drag.

- Increased wave drag at high Mach number and cant angle $80^{\circ}$.

- Noticeable reduction of $C_{L_{\max }}$ and lift curve slope for a winglet cant angle of $80^{\circ}$.

- Increased weight due to the device itself.

- The addition of the winglet will require a structural study in order to support the local forces and bending moments at the winglet junction.

- A new structural study of the wing to meet the new bending moments and flutter and fatigue requirements due to the addition of the winglet.

It is clear that to obtain the best trade-off between benefits and shortcomings, a multi-disciplinary design optimization study should be conducted, together with the use of more realistic wing geometries and additional winglet design variables, such as toe-angle, taper ratio, and span. We also envisage conducting a flight performance study using more realistic wing-winglet configurations. Nevertheless, the concept studied in this manuscript represents an innovative approach that might help in addressing the challenge of improving aircraft fuel efficiency, reduce pollutant emissions, and lowering the perceived external noise.

\section{References}

[1] Torenbeek, E. Advanced Aircraft Design: Conceptual Design, Analysis and Optimization of Subsonic Civil Airplanes, 2013, Wiley.

[2] Kroo, I. Drag due to lift: Concepts for prediction and reduction, Annual Review of Fluid Mechanics, 2001, 33, (1), pp 587-617.

[3] KRoo, I. Nonplanar wing concepts for increased aircraft efficiency, in: VKI lecture series on Innovative Configurations and Advanced Concepts for Future Civil Aircraft, 2005.

[4] Bertin, J. J. and Cummings, R. M. Aerodynamics for Engineers, 2013, Pearson.

[5] Jobe, C. E. Prediction of aerodynamic drag, Technical Report AFWAL-TM-884-203, Air Force Wright Aeronautical Laboratories, Wright-Patterson Air Force, Ohio, United States, 1984.

[6] NATO AGARD. Aircraft drag prediction and reduction, Technical Report AGARD report 723, NATO, 1985.

[7] FilipPone, A. Data and performances of selected aircraft and rotorcraft, Progress in Aerospace Sciences, 2000, 36, pp 629-654. 
[8] National Research Council. Assessment of Wingtip Modifications to Increase the Fuel Efficiency of Air Force Aircraft, The National Academies Press, Washington, DC, 2007.

[9] Guerrero, J. E., Maestro, D. and Bottaro, A. Biomimetic spiroid winglets for lift and drag control, Comptes Rendus Mecanique, 2012, 340, pp 67-80.

[10] JupP, J. Wing aerodynamics and the science of compromise, Aeronautical Journal, 2001, 105, pp 633-641.

[11] Chambers, J. R. Concept to reality: Contributions of the Langley research center to U.S. civil aircraft of the 1990s, NASA History Series SP-2003-4529, DIANE Publishing Company, Collingdale, PA, United States, 2003.

[12] Wнгтсомв, R. T. A design approach and selected wind tunnel results at high subsonic speeds for wing-tip mounted winglets, Technical Report NASA-TN-D-8260, NASA Langley Research Center, Hampton, VA, United States, 1976.

[13] McLean, D. Wingtip devices: what they do and how they do it, in: Presented at Boeing Performance and Flight Operations Engineering Conf., St. Louis, MO, United States, 2005.

[14] YIN, K.-S. A study of carbon dioxide emissions reduction opportunities for airlines on Australian international routes, Ph.D. thesis, 2017, University of Queensland.

[15] Boeing AERO magazine. Blended winglets improve performance, Quarter 3, 2009.

[16] NASA Spinoff Magazine, Winglets save billions of dollars in fuel costs, 2010.

[17] Strang, W. J. and McKinlay, R. M. Concorde in service, Aeronautical Journal, 1979, 83, pp 39-52.

[18] Cummings, R. M., Mason, W. H., Morton, S. A. and McDaniel, D. R. Applied Computational Aerodynamics. A Modern Engineering Approach, 2015, Cambridge University Press.

[19] van Dam, C. P. Aircraft design and the importance of drag prediction, in: VKI Lecture Series 2003: CFD-Based Aircraft Drag. Prediction and Reduction, 2003.

[20] Sankrithi, M. and Frommer, J. Controllable winglets, United States Patent US7744038B2. Issued: 2010-08-29.

[21] Моноцт, M. and Отнмаne, B. Spanwise adaptive wing, in: Presented at the 3rd Annual Convergent Aeronautics Solutions Showcase and Innovation Faire, VA, United States, 19-20 September, 2017.

[22] KaMLET, M. NASA tests new alloy to fold wings in flight, https://www.nasa.gov/centers/armstrong/ feature/nasa-tests-new-alloy-to-fold-wings-in-flight.html Last accessed: December 2018.

[23] NewScientist, Morphing winglets to boost aircraft efficiency, Volume 201, Issue 2692, 2009.

[24] Hubler, M., Nissle, S., Gurka, M. and Breuer, U. Fiber-reinforced polymers with integrated shape memory alloy actuation: an innovative actuation method for aerodynamics applications, CEAS Aeronautical Journal, 2016, 7, pp 567-576.

[25] Pankonien, A. M. Smart material wing morphing for unmanned aerial vehicles, Ph.D. thesis, 2015, University of Michigan.

[26] Allen, J. Articulating winglets, United States Patent US5988563A. Issued: 1999-11-23.

[27] Fox, S., Kordel, J., Townsend, K., Lassen, M., Gardner, M. and Good, M. Wing fold system rotating latch, United States Patent US9469392B2. Issued: 2016-10-18.

[28] Axford, T., Fong, T. and Alexander, S. An aircraft with a foldable wing tip device, Great Britain Patent GB201407197D0. Issued: 2014-08-11.

[29] BraY, R. Winglet, United States Patent US7988099B2. Issued: 2011-08-02.

[30] Boeing Commercial, Video: Boeing 777x folding wingtip https://www.boeing.com/777x/reveal/ video-777x-Folding-Wingtip/ Last accessed: December 2018.

[31] Wilson, T., Herring, H., Pattinson, J., Castrichini, A., Ajaj, R. and Dhoru, H. An aircraft wing with a movable wing tip device for load alleviation, Great Britain Patent GB2546246A. Issued: 2017-07-19.

[32] Dees, P. and Sankrithi, M. Wing load alleviation apparatus and method, United States Patent US20070114327A1. Issued: 2007-05-24.

[33] Guida, N. Active winglet, United States Patent US7900877B1. Issued: 2011-03-08.

[34] Guida, N. Adjustable lift modification wingtip, United States Patent US20160009378A1. Issued: 2016-01-14.

[35] Whitaker, R. H. Flight control device for airplanes, United States Patent US4455004A. Issued: 1984-06-19.

[36] Miller, E. J., Lokos, W. A., Cruz, J., Crampton, G., Stephens, C. A., Kota, S., Ervin, G. and Flick, P. Approach for structurally clearing an adaptive compliant trailing edge flap for flight, in: 46th Society of Flight Test Engineers International Annual Symposium, Lancaster, CA, United States, 14-17 September, 2015. 
[37] Kota, S., Osborn, R., Ervin, G. and Maric, D. Mission adaptive compliant wing - design, fabrication and flight test, in: In proceedings of the RTO Applied Vehicle Technology Panel (AVT) Symposium, Evora, Portugal, 20-24 April, 2009.

[38] Кота, S. Future airplanes will fly on twistable wings, IEEE Spectrum, August edition, 2016.

[39] Flexsys Inc. Flexfoil compliant control surfaces, https://wwW . flxsys . com/flexfoil/. Last accessed: December 2018.

[40] George, F. Aviation partners, flexsys to bring wing morphing to market, http://aviationweek.com/ nbaa-2015/aviation-partners-flexsys-bring-wing-morphing-market. Last accessed: December 2018.

[41] ERwIN, J. Method and apparatus for controlling tip vortices, United States Patent US3997132A. Issued: 1976-1214.

[42] Patterson, J. Wingtip vortex propeller, United States Patent US4533101A. Issued: 1985-08-06.

[43] Gerhardt, H. A. Wingtip vortex device for induced drag reduction and vortex cancellation, United States Patent US5934612A. Issued: 1999-08-10.

[44] Tonnessen, R., Cordier, S. and Storteig, E. Method and apparatus for reducing and extracting wing-tip vortex energy, United States Patent US727021B1. Issued: 2007-09-18.

[45] Roques, S. A system for recovering and converting kinetic energy and potential energy as electrical energy for an aircraft, United States Patent US9828110B2. Issued: 2017-11-28.

[46] Barriety, B. Aircraft with active control of the warping of its wings, United States Patent US6827314B2. Issued: 2004-12-07.

[47] Bourdin, P., Gatto, A. and Friswell, M. I. Aircraft control via variable cant-angle winglets, Journal of Aircraft, 2008, 45, (2), pp 414-423.

[48] BeEchook, A. and WANG, J. Aerodynamic analysis of variable cant angle winglets for improved aircraft performance, in: 19th International Conference on Automation and Computing, London, UK, 13-14 September, 2013.

[49] Panagiotou, P., Efthymiadis, M., Mitridis, D. and Yakinthos, K. A CFD-aided investigation of the morphing winglet concept for the performance optimization of the fixed-wing male UAVs, in: AIAA Applied Aerodynamics Conference, Atlanta, GA, United States, 25-29 June, 2018.

[50] Schmitt, V. and Charpin, F. Pressure distributions on the Onera-M6-wing at transonic Mach numbers, Technical Report AGARD report 138, NATO, 1979.

[51] Langley Research Center Turbulence Modeling Resource. Turbulence modeling resource - 3D Onera M6 wing validation, https://turbmodels.larc.nasa.gov/onerawingnumerics_val.html Last accessed: December 2018 .

[52] Advisory Council for Aviation Research and Innovation in Europe. European aeronautics: A vision for 2020, Technical Report of the Group of Personalities, Brussels, Belgium, 2001.

[53] Krein, A. and Williams, G. Flightpath 2050: Europe's vision for aeronautics, Innovation for Sustainable Aviation in a Global Environment: Proceedings of the Sixth European Aeronautics Days, IOS Press, Amsterdam, The Netherlands, 2012, p. 63.

[54] McCormick, B. W. Aerodynamics, Aeronautics, and Flight Mechanics, 1994, Wiley.

[55] Shollenberger, C. A. Application of an optimized winglet configuration to an advanced commercial transport, Technical Report NASA-CR-159156, NASA, Washington DC, United States, 1979.

[56] Smith, L. and CAmpbell, R. Effects of winglets on the drag of a low-aspect-ratio configuration, Technical Report NASA-TP-3563, NASA, Washington DC, United States, 1996.

[57] TAYLor, A. B. DC-10 winglet flight evaluation, Technical Report NASA-CR-3748, NASA, Washington DC, United States, 1983.

[58] Hicken, J. E. and ZINGG, D. W. Induced-drag minimization of non-planar geometries based on the euler equations, AIAA Journal, 2010, 48, (11), pp 2564-2575.

[59] WILcox, D. C. Turbulence Modeling for CFD, 2010, DCWIndustries.

[60] Wilcox, D. C. Formulation of the $\kappa-\omega$ turbulence model revisited, AIAA Journal, 2008, 46, pp $2823-2838$.

[61] Menter, F. R. Two-equation eddy-viscosity turbulence models for engineering applications, AIAA Journal, 1994, 32, pp 1598-1605. 
[62] Ansys. Ansys academic research, release 19, help system, ansys fluent theory guide, ansys, inc.

[63] BARTh, T. J. and Jespersen, D. The design and application of upwind schemes on unstructured meshes, in: AIAA 27th Aerospace Sciences Meeting, Reno, NV, United States, 9-12 January, 1989.

[64] Kim, S., CARAeni, D., and Makarov, B. A multidimensional linear reconstruction scheme for arbitrary unstructured grid, in: AIAA 16th Computational Fluid Dynamics Conference, Orlando, FL, United States, 23-26 June, 2003.

[65] Ferziger, J. H. and Peric, M. Computational Methods for Fluid Dynamics, 2001, Springer-Verlag.

[66] Patankar, S. V. and Spalding, D. B. A calculation procedure for heat mass and momentum transfer in three dimensional parabolic flows, International Journal of Heat and Mass Transfer, 1972, 15, pp 1787-1806.

[67] Lovely, D. and Haimes, R. Shock detection from computational fluid dynamics results, in: AIAA 14th Computational Fluid Dynamics Conference, Norfolk, VA, United States, 1-5 November, 1999.

[68] Destarac, D. and van der Vooren, J. Drag/thrust analysis of jet-propelled transonic transport aircraft; definition of physical drag components, Aerospace Science and Technology, 2004, 8, (6), pp. 545-556. 